\title{
Joint Practice Guidelines for Radionuclide Lymphoscintigraphy for Sentinel Node Localization in Oral/Oropharyngeal Squamous Cell Carcinoma
}

L. W. T. Alkureishi ${ }^{1}$, Z. Burak ${ }^{3}$, J. A. Alvarez ${ }^{4}$, J. Ballinger ${ }^{5}$, A. Bilde ${ }^{6}$, A. J. Britten ${ }^{7}$, L. Calabrese ${ }^{8}$, C. Chiesa ${ }^{9}$, A. Chiti ${ }^{10}$, R. de Bree ${ }^{11}$, H. W. Gray ${ }^{12}$, K. Hunter ${ }^{13}$, A. F. Kovacs ${ }^{1415}$, M. Lassmann ${ }^{16}$, C. R. Leemans ${ }^{11}$, G. Mamelle ${ }^{17}$, M. McGurk ${ }^{18}$, J. Mortensen ${ }^{6}$, T. Poli ${ }^{19}$, T. Shoaib ${ }^{2}$, P. Sloan ${ }^{20}$, J. A. Sorensen ${ }^{21}$, S. J. Stoeckli ${ }^{22}$, J. B. Thomsen ${ }^{21}$, G. Trifiro ${ }^{23}$, J. Werner ${ }^{24}$, G. L. Ross ${ }^{25}$ and The European Association of Nuclear Medicine (EANM) Oncology Committee and European Sentinel Node Biopsy Trial (SENT) Committee

${ }^{1}$ Department of Plastic Surgery, University of Chicago Medical Center, Chicago; ${ }^{2}$ Canniesburn Department of Plastic and Reconstructive Surgery, Glasgow Royal Infirmary, Glasgow, UK; ${ }^{3}$ Department of Nuclear Medicine, Ege University Medical Faculty, Bornova-İzmir, Turkey; ${ }^{4}$ Department of Oral and Maxillofacial Surgery, Hospital de Cruces, Universidad del Pais Vasco/EHU, Bilbao, Spain; ${ }^{5}$ Department of Nuclear Medicine, Guy's \& St Thomas' NHS Foundation Trust, London, UK; ${ }^{6}$ Department of Otolaryngology-Head and Neck Surgery, Copenhagen University Hospital, Copenhagen, Denmark; ${ }^{7}$ Medical Physics Department, St Georges Hospital, London, UK; ${ }^{8}$ Head and Neck Surgery Division, European Institute of Oncology, Milan, Italy; ${ }^{9}$ Nuclear Medicine Division, Department of Diagnostic Imaging and Therapy, Istituto Nazionale Tumori IRCCS Foundation, EANM Dosimetry Committee, Milan, Italy; ${ }^{10}$ Department of Nuclear Medicine, IRCCS Humanitas, Rozzano, Milan, Italy; ${ }^{11}$ Department of Otolaryngology/Head and Neck Surgery, VU University Medical Center, Amsterdam, The Netherlands; ${ }^{12}$ Department of Nuclear Medicine, Glasgow Royal Infirmary, Glasgow, UK; ${ }^{13}$ Department of Oral Pathology, University of Sheffield, Sheffield, UK; ${ }^{14}$ Nauheim, Germany; ${ }^{15}$ Department of Cranio-Maxillofacial Plastic Surgery, Goethe-University Medical School, Frankfurt am Main, Germany; ${ }^{16}$ Department of Nuclear Medicine, University of Wuerzburg, Wuerzburg, Germany; ${ }^{17}$ Département de Chirurgie Cervico-faciale, Institut Gustave Roussy, VilleJuif, France; ${ }^{18}$ Department of Oral and Maxillofacial Surgery, Guy's Hospital, London, UK;

${ }^{19}$ Maxillofacial Surgery Section, Head and Neck Department, Azienda Ospedaliero-Universitaria of Parma, Parma, Italy;

${ }^{20}$ Department of Cellular Pathology and School of Dental Sciences, Royal Victoria Infirmary and Newcastle University, Newcastle upon Tyne, UK; ${ }^{21}$ Department of Plastic Surgery, Odense University Hospital, Odense, Denmark; ${ }^{22}$ Department of Otorhinolaryngology, Head, and Neck Surgery, Kantonsspital St. Gallen, St. Gallen, Switzerland; ${ }^{23}$ Division of Nuclear Medicine, European Institute of Oncology, Milan, Italy; ${ }^{24}$ Department of Otolaryngology, Head, and Neck Surgery, Philipps-University Marburg, Marburg, Germany; ${ }^{25}$ Department of Plastic Surgery, Christie Hospital, Wilmslow, Manchester, UK

\begin{abstract}
Involvement of the cervical lymph nodes is the most important prognostic factor for patients with oral/

This article appears simultaneously in the November 2009 issues of European Journal of Nuclear Medicine and Molecular Imaging, Volume 36, Number 11 and Annals of Surgical Oncology, Volume 16, Number 11.
\end{abstract}

(C) The Author(s) 2009. This article is published with open access at Springerlink.com

First Received: 23 July 2009;

Published Online: 1 October 2009

L. W. T. Alkureishi

e-mail: lee_alkureishi@hotmail.com oropharyngeal squamous cell carcinoma (OSCC), and the decision of whether to electively treat patients with clinically negative necks remains a controversial topic. Sentinel node biopsy (SNB) provides a minimally invasive method for determining the disease status of the cervical node basin, without the need for a formal neck dissection. This technique potentially improves the accuracy of histologic nodal staging and avoids overtreating three-quarters of this patient population, minimizing associated morbidity. The technique has been validated for patients with OSCC, and larger-scale studies are in progress to determine its exact role in the management of this patient population. This document is designed to outline the current best practice guidelines for the 
provision of SNB in patients with early-stage OSCC, and to provide a framework for the currently evolving recommendations for its use. Preparation of this guideline was carried out by a multidisciplinary surgical/nuclear medicine/pathology expert panel under the joint auspices of the European Association of Nuclear Medicine (EANM) Oncology Committee and the Sentinel European Node Trial (SENT) Committee.

Keywords Sentinel lymph node biopsy - Carcinomas, squamous cell · Head and neck neoplasms - Technetium Tc-99m human serum albumin colloid · Radionuclide imaging

$\begin{array}{ll}\text { Abbreviations } \\ \text { SNB } & \text { Sentinel node biopsy } \\ \text { OSCC } & \begin{array}{l}\text { Oral/oropharyngeal squamous cell } \\ \text { carcinoma }\end{array} \\ & \text { European Association of Nuclear Medicine } \\ \text { EANM } & \text { European Sentinel Node Trial group } \\ \text { SENT } & \text { Elective neck dissection } \\ \text { END } & \text { Sentinel lymph node } \\ \text { SLN } & \text { Clinical node-negative } \\ \text { cN0 } & \text { Pathological node-negative } \\ \text { pN0 } & \text { Clinical node-positive } \\ \text { cN+ } & \text { Pathological node-positive } \\ \text { pN+ } & \text { Technetium-99 } \\ \text { Tc-99m } & \text { Lymphoscintigraphy } \\ \text { LSG } & \text { Computed tomography } \\ \text { CT } & \text { Magnetic resonance imaging } \\ \text { MRI } & \text { Ultrasound-guided fine-needle aspiration } \\ \text { USg-FNAC } & \text { cytology } \\ & \text { 18F-fluoro-deoxyglucose positron emission } \\ \text { FDG-PET } & \text { tomography } \\ & \text { FDG-PET with low-dose CT } \\ \text { PET/CT } & \text { Megabecquerel } \\ \text { MBq } & \text { Microgray } \\ \mu \text { Gy } & \text { Millisievert } \\ \text { mSv } & \text { Microsievert } \\ \mu \text { Sv } & \text { Kilo-electron-volt } \\ \text { keV } & \text { Single-photon emission computed } \\ \text { SPECT } & \text { tomography } \\ \text { IV } & \text { Intravenous } \\ \text { ICRP } & \text { International Commission on Radiological } \\ & \text { Protection } \\ 57 C o & \text { Cobalt-57 } \\ 153 G d & \text { Gadolinium-153 } \\ \text { cps } & \text { Counts per second } \\ \text { QA } & \text { Uality assurance } \\ \text { QC } & \text { Quality control } \\ \text { UICC } & \text { Union Internationale Contre le Cancer } \\ & \text { (International Union against Cancer) } \\ \text { H\&E } & \text { Hematoxylin-eosin stain } \\ & \end{array}$

MM

ITC

RT-PCR

\section{Micrometastasis}

Isolated/individual tumor cells

Reverse-transcriptase polymerase chain reaction

Oral/oropharyngeal squamous cell cancer (OSCC) is one of the most common cancers worldwide, with more than 274.000 new cases annually. ${ }^{1}$ Three-quarters of cases affect people in the developing world, while in developed countries, OSCC is the eighth most prevalent form of cancer.

Determining the presence or absence of nodal metastasis is of paramount importance for staging, treatment planning, and prognosis. The incidence of occult metastases in patients with clinically node-negative (cN0) OSCC is high, with many series reporting rates greater than $30 \% .^{2-5}$ Cervical lymph node involvement is the most important prognostic factor for patients with OSCC. ${ }^{5-7}$

Elective treatment of the clinically negative neck remains a controversial topic. Over the last two decades much work has been undertaken to find reliable predictors of occult metastases, of which tumor depth appears to be the best available. ${ }^{8-11}$ However, the predictive capacity of tumor depth and other primary tumor characteristics are still insufficient to negate the need for surgical staging of the cervical node basin. ${ }^{12,13}$

Elective neck dissection (END) is the current gold-standard staging procedure for the $\mathrm{cN} 0$ neck, providing valuable prognostic information regarding nodal status and simultaneously treating those patients found to be node positive $(\mathrm{pN}+)$. Previously, ENDs invariably took the form of a modified radical neck dissection, however there is increasing evidence that selective neck dissection is as efficacious as comprehensive neck dissection in treating the negative neck. ${ }^{2,14-20}$ The shift toward more conservative surgical procedures has occurred primarily in the last two decades, facilitated by the work undertaken by Lindberg, Byers, and Shah to describe the common patterns of lymphatic drainage. ${ }^{3,21,22}$ Knowledge of these patterns has allowed the extent of neck dissections to be progressively limited to those nodal levels at highest risk, and sentinel node biopsy (SNB) represents an extension of this philosophy.

The aim of this review is to provide an evidence-based guideline for the use of sentinel node biopsy as a staging tool for patients with early OSCC, presenting the best available evidence at the time of writing.

The existing literature was reviewed, utilizing electronic techniques (Medline, Best Evidence, the Cochrane Library, Dare) and hand-searching techniques. Where little or no data existed from randomized controlled prospective trials, emphasis was given to data from large series or reports from recognized experts in the field. It is recognized that 
higher-level evidence from future studies may modify the recommendations made in this manuscript.

\section{DEFINITION OF A SENTINEL NODE}

The sentinel node concept states that the spread of a tumor is embolic in nature, via the lymphatics to the firstechelon lymph node(s) encountered in the regional draining basin. These represent the lymph nodes most likely to harbor occult metastases, and are designated the sentinel lymph nodes (SLNs). Excisional biopsy and pathological evaluation of the SLNs therefore allows for prediction of the disease status of the remaining cervical lymph node basin, potentially avoiding the need for a neck dissection. Sentinel lymph nodes need not be those closest to the tumor, and there may be multiple SLNs. ${ }^{23}$ With the application of early dynamic lymphoscintigraphy, lymphatic channels are usually visualized, and nodes on a direct drainage pathway may be distinguished. The practical approach may include the combination of available detection techniques.

Lymphatic mapping and sentinel node biopsy (SNB) were first reported in 1977 by Cabanas for penile cancer. ${ }^{24}$ In 1992, Morton and colleagues first described the use of intradermal isosulfan blue dye injection for lymphatic mapping and SLN localization in patients with malignant melanoma. ${ }^{23}$ The following year, Alex et al. described a peritumoral intradermal injection of radioactive tracer ${ }^{99} \mathrm{~m}$ technetium sulfur colloid), followed by imaging and intraoperative gamma probe radiolocalization of SLNs. ${ }^{25}$ The sentinel node concept has since been extensively studied and validated for patients with cutaneous melanoma and breast cancer. ${ }^{26,27}$ Studies to date have also indicated a high level of accuracy in patients with OSCC. ${ }^{28,29}$

\section{CLINICAL INDICATIONS}

\section{Inclusion Criteria}

The most important inclusion criterion for SNB is a clinically negative neck, as defined by physical examination and clinical imaging by computed tomography (CT), contrast-enhanced magnetic resonance imaging (MRI), ultrasound-guided fine-needle aspiration cytology (USgFNAC), and/or 18F-fluoro-deoxyglucose (FDG) positron emission tomography (PET) with or without low-dose CT (PET/CT) ${ }^{30,31}$ There remains considerable debate on the preferred imaging modality, and to date none have the ability to detect small or micrometastatic tumor deposits, but all techniques improve on the sensitivity of palpation alone and are therefore recommended prior to SNB. Recently, the high specificity of PET has been highlighted as an important means of avoiding unnecessary neck dissections. ${ }^{30}$ Gross lymphatic involvement can lead to distortion of the normal architecture, leading to aberrant drainage patterns and biopsy of false sentinel nodes. ${ }^{32}$ SNB is therefore contraindicated to stage clinically positive necks.

Following the first report of SNB for OSCC, the technique has undergone extensive validation against the gold-standard END, for tumors located in the oral cavity and accessible subsites of the oropharynx. ${ }^{29,33,34}$ It has been demonstrated to be an accurate means of staging the clinically negative neck, and more recently the potential prognostic value of SNB for these tumor sites has also been highlighted. ${ }^{35}$ While SNB has been successfully reported for tumors in other locations such as the hypopharynx and supraglottic larynx, there remain significant technical barriers, and SNB for these sites should therefore still be considered investigational. ${ }^{36}$ Poor access to these sites requires general anesthesia and endoscopic guidance for radiotracer injection, precluding the use of preoperative lymphoscintigraphy (LSG), while the close proximity of the primary tumor to the first-echelon lymph nodes can potentially obscure the true location of SLNs. Additionally, advanced stage at presentation is common for these hidden tumors, precluding the use of SNB or indeed any surgical intervention.

There is an existing consensus that SNB for OSCC should be restricted to early tumors staged T1/2. ${ }^{37-39}$ Larger tumors are difficult to completely surround with the tracer injection, tend to drain to multiple lymphatic basins, and in most patients require a neck dissection for access to the primary tumor or defect reconstruction. Inclusion of T3/T4 tumors in study protocols can lead to variability in the accuracy of the technique. ${ }^{37}$

The first and most frequent indication for SNB is to stage the ipsilateral cNO neck in patients with a unilateral primary tumor. A second indication is for assessment of bilateral cN0 necks in primary tumors close to, or crossing, the midline. The third indication is for assessment of the contralateral $\mathrm{cN} 0$ neck in primary tumors close to the midline with an ipsilateral $\mathrm{cN}+$ neck, in order to decide whether these patients need bilateral neck dissections, or an ipsilateral neck dissection and contralateral SNB only. Patients should also be fit enough preoperatively to withstand a neck dissection.

Patients who have received prior radiation or surgical treatment to the neck are routinely excluded from SNB protocols, since the previous intervention can distort the normal lymphatic pathways and give rise to unexpected patterns of metastasis. It is possible that lymphatic mapping and SNB may yield potentially useful information in these patients. Similarly, patients with small recurrent or second primary tumors may also benefit from lymphatic mapping to guide surgical intervention. However, these applications of the SNB technique, whilst clinically attractive, remain largely unexplored. 


\section{Exclusion Criteria}

In pregnant women, the urgency and the necessity of staging the neck should be discussed. Lymphoscintigraphy is specifically contraindicated in the pelvis of pregnant women, but no such recommendations are currently available for the head and neck. As discussed in the "Dosimetry" section, the risk of fetal damage is negligible during routine SNB procedures. However, SNB protocols should be modified in pregnant patients to minimize risks of radiation exposure and blue-dye injections. For example, the use of a 1-day protocol allows a lower injected radiation dose, and the additional radiation associated with SPECT/CT imaging may not be warranted in the pregnant patient. SNB can be performed in lactating women, but it is advised that breastfeeding be discontinued following the procedure. OSCC is rare in children, though each case should be treated individually. In the UK, Nanocolloid is approved for use in children, though licencing varies between countries. The potential benefits of sentinel node biopsy are not as well delineated in the pediatric population and, in practice, most SNB trial protocols generally exclude these patients from participation. Off-label use of radiopharmaceuticals should be considered with caution and with respect to an individual risk-benefit analysis. Other relative contraindications include known allergy to albumin colloid, and primary tumor treatment by external-beam radiotherapy.

In summary, SNB is currently indicated for cT1/2, cN0 oral, and select oropharyngeal SCC, where it may be considered a valid alternative to elective neck dissection. Other head and neck sites, histologies, and clinical situations remain under investigation.

\section{RADIOPHARMACEUTICALS}

\section{Introduction}

A variety of colloidal and soluble tracers have been used over the years for lymph studies. It is believed that radiocolloids are taken up by macrophages in lymph nodes whereas the transit of macromolecules through lymph nodes is delayed simply because of their large molecular size. ${ }^{40}$

\section{Choice of Radiopharmaceutical}

The main radiopharmaceutical used in European studies of sentinel node localization in oral cancers is Tc-99mlabeled human serum albumin colloid (Nanocoll ${ }^{\circledR}$ ) (GE Healthcare). Nanocoll ${ }^{\circledR}$ has a particle size range of 5$80 \mathrm{~nm}$, with a reported mean size of $8-30 \mathrm{~nm} .{ }^{40}$ Although in theory a larger particle such as Albures ${ }^{\circledR}$ (GE Healthcare) or Sentiscint ${ }^{\circledR}$ (Medi-Radiopharma) may be preferred for tumors in the floor of mouth or anterior tongue where lymphatic densities are high, Nanocoll ${ }^{\circledR}$ performs satisfactorily in all tumor types studied. ${ }^{37}$ Nanocoll $^{\circledR}$ migrates to the sentinel node within minutes, yet prolonged retention allows surgery to take place the following day.

Other radiocolloids which have been used include Tc99 m rhenium sulfide colloid (Nanocis ${ }^{\circledR}$, IBA), which has been shown to have a mean particle size of $23-25 \mathrm{~nm}{ }^{41}$ Tc-99 $\mathrm{m}$ sulfide colloid has also been used. Standard preparations of Tc-99 $\mathrm{m}$ sulfide colloid result in a wide range of particle sizes, so the product is often filtered through a 100- or 200-nm membrane filter to obtain a smaller and more uniform size distribution. While there are currently no clinical studies comparing different radiopharmaceuticals, investigators have described satisfactory results with each of the available colloids. ${ }^{42,43}$

\section{Preparation and Quality Control}

Nanocoll $^{\circledR}$ is labeled by incubation with Tc-99 m pertechnetate at room temperature for 30 min. ${ }^{44}$ Radiochemical purity can be checked by thin-layer chromatography, and labeling efficiency should be $>95 \%$. The EANM guidelines on current good radiopharmacy practice (cGRPP, www.eanm.org) recommend that labeling efficiency be checked on each preparation. The stated expiry is $6 \mathrm{~h}$ after preparation, although extended stability has been demonstrated. $^{45}$

\section{Drug Interactions and Adverse Effects}

No interactions of drugs with radiocolloids are expected following local intradermal or subcutaneous application. Adverse effects are rare and mild following interstitial application of radiocolloids, although allergic reactions have been reported with Nanocoll and the blue dyes used at surgery. ${ }^{46-48}$ The incidence of allergic reactions is too low to quantify, but appropriate emergency medicines should be kept available during the procedure.

\section{Summary}

Tc-99 m-labeled Nanocoll ${ }^{\circledR}$ is easy to prepare and supply, and has suitable properties for sentinel node localization in oral cancers, with rapid migration to the sentinel node and prolonged retention.

\section{DOSIMETRY: PATIENT}

\section{General Remarks}

Presently available dosimetric data are derived from the breast cancer SNB literature, where the absorbed doses to patients are determined to be low; therefore, the radiation risk 
associated with this procedure is low. While no specific OSCC data exist, the radiopharmaceuticals and administered activity are identical, leading to the assumption that OSCC SNB is a safe procedure from the radiation protection point of view.

\section{Patient Exposure}

The estimated local radiation dose varies greatly, depending on the administered dose and time to surgery. As mentioned in the "Injection" section, there is little consensus on the optimal administered dose and timing of surgery relative to the radiocolloid injection. Most centers perform LSG within $24 \mathrm{~h}$ of surgery, but recommendations for administered activity range from $15 \mathrm{MBq}$ (for a sameday procedure) to $120 \mathrm{MBq}$ (for a 2-day procedure) in a total injection volume of $0.4-1.0 \mathrm{ml}$. The aim is to achieve an activity of at least $10 \mathrm{MBq}$ at the time of surgery. ${ }^{49,50}$ Current EANM guidelines for SNB in breast cancer report a mean value for the effective dose of $0.048 \mathrm{mSv} .{ }^{51}$ While other authors have reported doses approximately tenfold higher, these remain low compared with other nuclear medicine procedures. ${ }^{52}$ Extensive calculations performed by the Memorial Sloan-Kettering Cancer Center have confirmed the safety of SNB by reporting an effective dose around $0.2 \mathrm{mSv}^{53}$

\section{Fetal Exposure}

The maximum value for fetal absorbed dose has been calculated to be $0.013 \mathrm{mSv}$ following injection of 18.5 MBq. ${ }^{53}$ This dose is equivalent to that received by the mother from 1 day of natural background radiation in the USA, and is orders of magnitude below the 100-200-mSv threshold for deterministic effects (malformation, growth retardation, neurodevelopmental abnormalities). ${ }^{52,54}$ Current consensus is that noncancer health effects are not detectable below $50 \mathrm{mSv}$, while congenital malformations occur above $200 \mathrm{mSv} .{ }^{53}$ With respect to childhood cancer induction (stochastic effect), the International Commission on Radiological Protection (ICRP) reports a threshold of $10 \mathrm{mSv}$ for a $40 \%$ risk increase. $^{54}$

In summary, the advantages of SNB for OSCC outweigh the potential risks of the absorbed radiation dose, and this is also true for pregnant patients. While SNB is not contraindicated in pregnant patients, it is preferable to use a same-day protocol, enabling a lower injected dose. ${ }^{50}$

\section{Lactating Women}

The current recommendation is that nursing mothers should suspend breast-feeding for $24 \mathrm{~h}$ following radiopharmaceutical injection, during which time the general anesthetic agent and radiocolloid will be excreted in breast milk. ${ }^{51}$

\section{DOSIMETRY: STAFF}

\section{Staff in Operating Room}

Studies in breast and melanoma patients have determined the mean whole-body dose received by surgical staff to be $<1 \mu \mathrm{Sv}$ per operation, with the maximum dose to the surgeon of $<2 \mu \mathrm{Sv}^{52,55-57}$ The absorbed doses are further minimized when SNB is performed at $24 \mathrm{~h}$ after injection. ${ }^{58}$ Monitoring of operating room personnel for occupational exposure during the procedure is therefore unnecessary, and additional shielding is not required. While the pregnant surgeon or scrub nurse requires specific consideration, participation in fewer than 100 SNB operations during the gestation will remain below the recommended radiation exposure limits for pregnant women. ${ }^{57}$

\section{Staff in Pathology Department}

Radiation exposure to pathology staff is very low, and should not require badge monitoring. Even personnel performing unusually high numbers of procedures receive radiation doses well below established limits for members of the general public. ${ }^{59}$

\section{Radiation Safety Precautions}

Labeling specimens as radioactive for transportation to the laboratory is not required, since the surface dose rate is $<5 \mu \mathrm{Gy} / \mathrm{h}^{60}$

\section{Radioactive Clinical Waste}

Surgical instruments and pathology slides appear to stay at background radiation levels, while measurable contamination of absorptive surgical sponges and other materials used in proximity to the injection site is observed ${ }^{61}$ It is advisable to monitor these materials for contamination, and contaminated materials should be held for an appropriate period of decay in storage before disposal. ${ }^{52,59}$

\section{INJECTION}

The lymphatic anatomy within the oral cavity and oropharynx is extremely complicated and varies significantly between subsites, emphasizing the need for precise injection technique. ${ }^{39,62,63}$

\section{Patient Preparation}

No special preparation is needed. Patients should be fully informed about the procedure, including discussion of 
potential problems such as bleeding and discomfort, before consent can be obtained.

\section{Syringe, Activity, and Volume}

Tuberculin syringes with minimal dead space are recommended; otherwise $0.1 \mathrm{~mL}$ air may be drawn into the syringe behind the radiocolloid to ensure complete administration. A 25- or 27-gauge needle should be used. The total activity to be injected may vary, depending on the size and location of the primary tumor. As described in the "Dosimetry" section, there is currently little consensus on the optimum activity for injection, and this varies considerably from 15 to $120 \mathrm{MBq}$ between studies. ${ }^{39,64,65}$ The total injected activity should be adjusted according to the timing of LSG with respect to surgery. Higher doses are required for a 2-day protocol, in order to ensure that the activity exceeds $10 \mathrm{MBq}$ at the time of surgery. ${ }^{50}$ Small volumes of $0.1-0.2 \mathrm{~mL}$ per aliquot are recommended to minimize contamination due to the resistance of tongue tissue. Contamination can be avoided by placement of a sheet over the injected region and a gauze swab over the needle puncture site before withdrawal. Following injection, the skin/mucosa should be checked for contamination.

\section{Injection Site and Depth, and Number of Injections}

Tracer should be injected at $0.1-0.5 \mathrm{~cm}$ from the tumor or scar margin. The number of aliquots to be injected varies (two to four) according to the size and location of the lesion. The tracer should be administered on each side of the tumor/scar, keeping as a reference the orientation of the surgical scar. For lesions in sites with abundant soft tissue (i.e., soft palate or floor of the mouth) four separate submucosal injections must be given around the lesion (at 3,6, 9, and 12 o'clock). For lesions located in muscle (i.e., tongue), injections should be performed according to the depth of the lesion. Ideally, the operating surgeon should be present for the injections to ensure consistency with injection of blue dye if used. Following injection, bleeding may be controlled with a gauze swab, and the patient should be asked to use a mouth rinse to minimize pooling of the radiotracer in the oral cavity. ${ }^{34}$

\section{IMAGING}

\section{Introduction}

Lymphoscintigraphy uses a gamma camera to assess the drainage of injected radiotracer via the lymphatic capillaries to the larger collector lymphatics until it either passes through, or is retained within, the regional lymph nodes. ${ }^{66}$ Accurate preoperative localization and cutaneous marking of the SLNs correlates well with the precision of the surgical procedure. ${ }^{67,68}$

\section{Cameras and Camera Settings (Quality Control)}

A large-field-of-view gamma camera equipped with a high- or ultrahigh-resolution low-energy collimator should be used, with a 10-20\% window centered on the $140-\mathrm{keV}$ energy peak of Tc-99 m. A two-headed camera allows simultaneous dynamic acquisition in the anterior and a lateral projection, and saves time for the static images and SPECT. ${ }^{69}$ Quality control for the gamma camera should be routinely performed and should follow published protocols. $^{70}$

\section{Image Acquisition}

Dynamic acquisition for $20-30 \mathrm{~min}$ (20 s per frame) with a $128 \times 128$ matrix or $256 \times 256$ matrix starting immediately after radiotracer injection will show the drainage pattern and help to differentiate between sentinel nodes, which can appear very early following injection, and second-echelon lymph nodes. ${ }^{69,71}$ Two (or three if a three-headed camera is used) simultaneous images in the anterior and lateral projections are recommended.

Static images in the anterior and lateral projections from one or both sides (and oblique as needed) are acquired ( $300 \mathrm{~s}$, with a $256 \times 256$ matrix) to localize the nodes in three dimensions. If hot nodes are not clearly depicted, static images can be repeated at, e.g., $2 \mathrm{~h}, 4-6 \mathrm{~h}$ or even just before surgery. The patient is imaged in the supine position with head up. A small flat pillow under the neck may help to fixate the head and neck area.

SPECT imaging may improve the identification of SLNs, especially close to the injection site. Lesion detectability is increased by attenuation and scatter correction, which is easily accomplished with hybrid SPECT/ CT devices. ${ }^{69,72}$ The increased anatomical detail provided with CT improves localization of SLNs to the anatomical neck level. ${ }^{69}$ SPECT acquisition parameters can be $128 \times$ 128 matrix, $180^{\circ}$ in the anterior L-mode rotation, $3^{\circ}$ angle step, with $20-25 \mathrm{~s}$ per projection or 60 steps per head, $30 \mathrm{~s}$ each, with slice thickness of $4.42 \mathrm{~mm} .^{69,73}$

CT acquisition parameters differ depending on the CT system used. To date, most reports on SPECT/CT for SNB in oral cancer have used a slow, low-end CT scanner (GE Hawkeye) with acquisition performed over $220^{\circ}$ using $16 \mathrm{~s}$ for each transaxial slice, with a fixed tube current of $2.5 \mathrm{~mA}, 140 \mathrm{kV}$, and slice thickness of $10 \mathrm{~mm} .{ }^{69,73}$ With fast, high-end CT scanners providing higher-quality CT scans, either a low dose or a higher dose of CT can be used. Low-dose parameters can be, e.g., $20 \mathrm{~ms}$ per slice, slice thickness/increment $3 / 3 \mathrm{~mm}$, and $120 \mathrm{kV}$. If a diagnostic 
CT scan is required, IV contrast can also be used. If CT images are used for attenuation correction, inspection of both uncorrected and attenuation-corrected SPECT images is recommended, to avoid overlooking contrast-induced artifacts on the latter.

A number of studies have reported advantages of adding SPECT/CT to planar imaging, including identification of missed SLNs, exclusion of ambiguous SLNs, and/or better anatomical localization in $30-47 \%$ of patients. ${ }^{69,73}$ However, it has been suggested that meticulous oblique planar imaging can visualize the additional SLNs seen with SPECT imaging, and this may represent an adequate alternative. ${ }^{74}$ Furthermore, a number of investigators have reported no advantage to SPECT imaging with respect to the number and location of visualized hotspots. ${ }^{75,76}$ The true role of SPECT imaging for OSCC SNB has yet to be determined. If used, SPECT/CT should not be a substitute for meticulous planar imaging technique.

The location of SLNs harvested during surgery does not always correlate perfectly with the preoperative imaging, though higher-quality CT images can allow visualization of individual SLNs $<1 \mathrm{~cm}$, leading to improved preoperative and intraoperative SLN localization. ${ }^{69,77}$

\section{Body Contouring}

To facilitate topographic localization, a 57Co flood source (or, if available, a $153 \mathrm{Gd}$ source) can be used for simultaneous transmission imaging in each projection. Since there is a risk of missing faint nodes when using a transmission source, it has been suggested to repeat the scan without a transmission source. ${ }^{78}$ Alternatively, a radioactive point source may be used to outline the patient's contour while recording the scan.

\section{Image Interpretation}

On dynamic imaging, SLNs are identified as one or more foci to which lymphatic drainage passes, and may be multiple, in one or several areas of the neck, ipsilateral and/ or contralateral to the primary tumor. ${ }^{79}$ Imaging should begin immediately, since SLNs can be seen in the first minute after injection. ${ }^{80}$ Foci appearing only on later images are also labeled as SLNs, and most appear within $1-3$ h. $^{74,81}$

According to some reports, SPECT/CT may identify a median of one additional SLN compared with planar imaging. In addition, SLNs located very close to the primary tumor may be detected by SPECT/CT but not with the gamma probe during surgery. ${ }^{69}$ While the benefits of SPECT/CT have not been universally accepted, both planar and SPECT images demonstrate good or excellent inter- and intraobserver agreement for evaluation of SLNs, with kappa values of $68-89 \%$. $^{74-76}$

\section{Nonvisualization}

SLNs are usually detected between 15 and 60 min after radiotracer injection. Failure to detect SLNs may be related to incorrect injection technique or close proximity of SLNs to the injection site (e.g., floor of mouth tumors). In addition, metastatic deposits may block lymphatic drainage, causing nonvisualization of SLNs. ${ }^{32,82}$ Repeat injection and imaging may be considered, however proceeding to neck dissection is preferred in order to avoid a false-negative SLN.

\section{Aberrant Nodes and In-Transit Sentinel Nodes}

Individual lymphatic mapping by lymphoscintigraphy is a major advantage of SNB, demonstrating occasional unexpected drainage to, e.g., level IV or contralateral metastases from well-lateralized tumors. ${ }^{64,74,82-90}$ In addition, LSG has been reported to detect "in-transit" lymph nodes: SLNs lying between the primary tumor and the regional lymph basin. ${ }^{91}$ These have been described in the context of malignant melanoma, but to date there have been no reports of in-transit SLNs in OSCC.

\section{REPORT AND DISPLAY}

\section{Introduction}

There are two main indications for careful report and display of the results from lymphoscintigraphy:

(1) unambiguous guidance for surgical biopsy, and (2) a comprehensive dataset for ongoing/future studies. ${ }^{37,74}$

\section{Report}

The type of radiocolloid, lot number, volume injected, and effective dose should be recorded, along with the initials and title of the nuclear medicine physician or surgeon performing the injection. The type of camera used and imaging technique should be described in detail: ${ }^{69}$

1. Start time for dynamic imaging;

2. Timing and location of the first-echelon node(s) that appear;

3. Timing and number of anterior, posterior, and oblique recordings;

4. Timing and location of any additional (second-echelon) nodes; these should be clearly differentiated from the first-echelon nodes; 
5. If CT or hybrid imaging is used, the manufacturer, software, and protocol should be described in detail. The number and location of nodes recorded by these modalities should be described and compared with planar recordings. It should be clearly stated if the results of the tomographic images differ from the planar recordings.

Shine-through from the primary tumor or opposite side should be described and marked clearly on the images. Increased absorption in the thyroid gland can be seen due to unstable colloid solution as a result of a colloid production error, and this may lead to difficulties in interpreting the lymphoscintigraphic images. ${ }^{92}$ Artifacts may also occur due to cutaneous contamination at the time of injection. ${ }^{93}$ Rarely, a widened lymphatic capillary may form a "colloid lake;" however, the associated hotspot will invariably disappear during subsequent imaging, in contrast with true SLNs.

\section{Display}

Lymphoscintigraphic findings should be summarized by the nuclear medicine physician, providing a clear, unambiguous report for preoperative consultation. In addition, hardcopy or digital copies of the LSG images should be available to the surgeon, both prior to and during surgery. ${ }^{37,74}$

\section{Skin Marking}

First-echelon nodes should be marked on the skin using one color of indelible marker, guided by gamma camera and handheld gamma probe. ${ }^{94}$ Second-echelon nodes should be marked with a different color, and clearly differentiated.

\section{USE OF DYE}

\section{Introduction}

The use of blue dye in head and neck mucosal cancer sentinel node surgery is optional. However, when used it is a useful adjunct to aid SLN localization and harvest. Blue dye cannot be used alone to perform OSCC SNB, but can be used in addition to radiolocalization with preoperative LSG and intraoperative gamma probe use. ${ }^{34}$

Following injection, blue dye drains to the SLNs via the same lymphatic pathways as radiocolloid, staining the channels, which can then be followed to the first-echelon nodes. Direct visualization and dissection of these channels is a natural process for the head and neck surgeon.

Rarely, nonradioactive blue nodes may contain metastases in the absence of a tumor-positive radioactive node; two such SLNs were reported in a series of 40 patients undergoing SNB with both radiocolloid and blue dye injection. ${ }^{63}$ The handheld gamma probe is more sensitive for the detection of sentinel nodes, and not all radioactive nodes will also appear blue. ${ }^{28}$ However, blue dye may aid the surgeon perform SNB, both for technical success of the procedure and for identification of subclinical nodal metastasis.

\section{Contraindications and Special Precautions}

Blue dye is contraindicated in children, pregnant women, lactating women, and those who have a history of allergy to the blue dye or any of its ingredients. It can, however, be used in all mucosal sentinel node procedures, for any malignant process for which the procedure has been deemed suitable, including OSCC.

\section{Blue Dyes}

In the UK and Europe, the blue dye used is Patent Blue V (Laboratoire Guerbet, Aulnay-Sous-Bois, France; Fig. 1) which comes in 2-ml vials at $2.5 \%$ concentration. Outside of Europe, the use of other agents such as Isosulfan Blue (Lymphazurin TM) is more common. Gloves should be worn to avoid staining, and a gauze swab used to prevent dye spillage where possible. The dye will rarely mask the edge of the tumor and, if this is a concern, the tumor edge can be marked prior to injection with staples or diathermy marks.

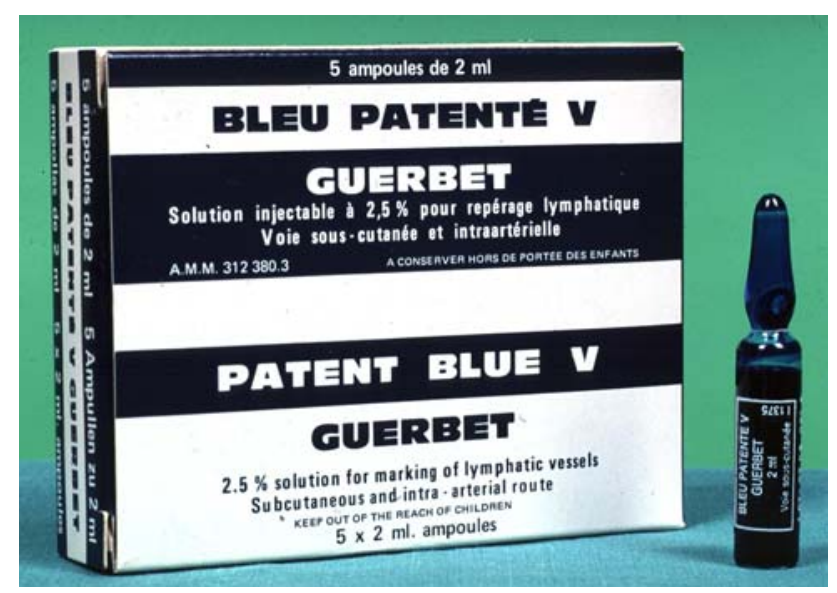

FIG. 1 Patent Blue V dye 


\section{TIMING OF INJECTION}

Patent Blue V dye is injected at the time of surgery, under general anesthetic. It takes approximately $10-15 \mathrm{~min}$ for a significant amount of dye to travel from the injection site to the sentinel node and this is the approximate time it takes to scrub, prepare the patient, make the initial excision, and begin to explore the neck. The patient and anesthetist should be informed that the dye will be excreted in the urine, and the urine will remain discolored for approximately 2 days.

\section{INJECTION TECHNIQUE}

One vial of dye is injected slowly into the tissues surrounding and deep to the tumor, to minimize leakage from ulcerated tumors. Gauze swabs may be used to protect normal tissue and mop up excess dye. The number of injections is usually between two and four, but is as many as is necessary to completely surround the tumor on its deep and lateral surfaces. Occasionally it may be necessary to grab the tongue with forceps or a retracting suture during the injection. The injection site should not be massaged, in order to maintain oncologic safety of the procedure.

\section{Adverse Effects}

Anaphylaxis and allergic reactions, while rare, are a possibility, and clinicians should be mindful of this during the injection. ${ }^{95}$ In the event of a reaction, the injection should be discontinued and appropriate resuscitation performed. A decision should be made as to whether to continue or abandon the procedure based on clinical findings and discussion between the surgeon and anesthetist. The mucosa is stained after injection, however the dye tends not to diffuse more than the margins of excision of the tumor and it has not been the authors' (T.S.) experience that dye interferes with pulse oximetry or pathologic interpretation of the excised tumor specimen. ${ }^{34}$

In summary, injection of blue dye is a useful adjunct to gamma probe localization of the sentinel node. It is an optional procedure, but one that offers significant advantages for OSCC SNB.

\section{GAMMA PROBE}

\section{Introduction}

There are a wide variety of gamma probes available with individual feature sets, each requiring specific training and information. In many countries, effective competency training is required as part of the regulations governing the use of radioactivity.

\section{Probe Components}

The gamma probe is a radiation detector, providing a count rate from gamma rays. The handheld probe contains the radiation detector, either a crystal or a solid-state device, with surrounding metal shielding and collimation to give a restricted field of view (Fig. 2). It is connected to a power supply and an analyzer unit which receives electrical signals from the radiation detector. The analyzer and handheld probe together form the probe system, which may be powered by mains connection or battery. The analyzer provides a response related to the detected count rate, usually by audible pitch or volume variation and by a visual display as a dial or digital count rate (counts per second, cps). The probe technology is described in a number of reference books. ${ }^{96-98}$

\section{Probe Size and Shape}

Probes typically have outer dimensions of $12-15 \mathrm{~mm}$, with smaller probes producing problems related to the smaller-less sensitive-detector, and less adequate shielding of the probe housing from gamma rays. Probe tips may be angled relative to the handle. This may be viewed as an advantage for minimal-access surgery, or a disadvantage due to surgeon preference.

\section{Probe Performance}

Probe performance is described in terms of its spatial resolution and its count sensitivity. ${ }^{99-101}$ Spatial resolution indicates how spread out the signal is from a point source;

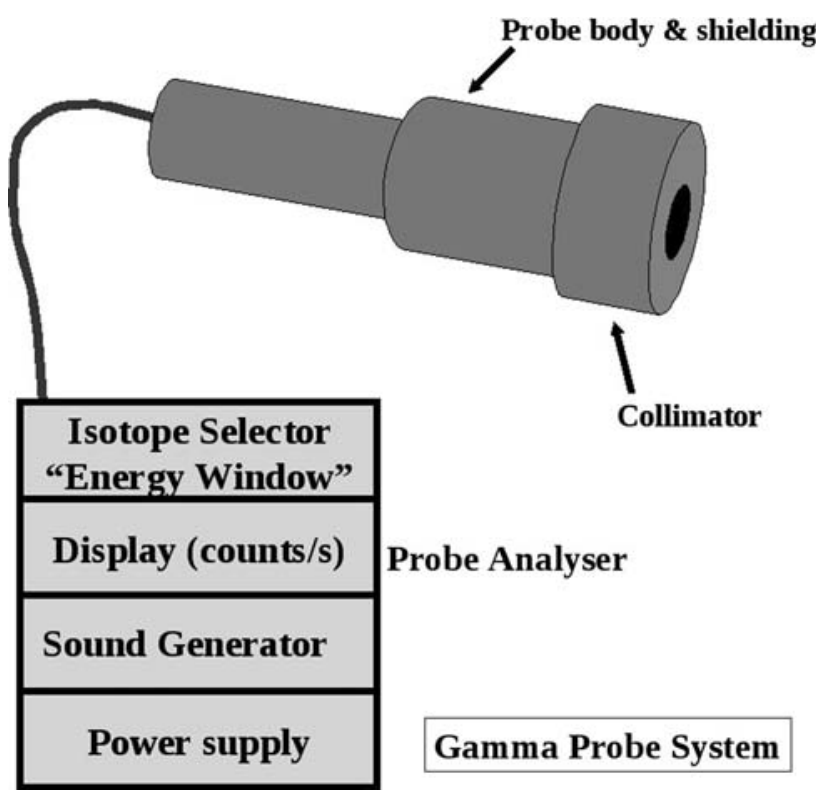

FIG. 2 Components of the gamma probe 
sensitivity is the number of cps for a given strength of source. At a typical node depth of $30 \mathrm{~mm}$, a point-source node will appear to be about $25 \mathrm{~mm}$ wide due to the imperfect spatial resolution of the probe, and resolution worsens with increasing distance. Many nodes contain well below $1 \%$ of the injected activity, and with a $6 \mathrm{~h}$ half-life of Tc-99 m the activity in a given node can be low, particularly if the surgery is delayed after injection of the radiopharmaceutical. A probe should be able to achieve sensitivity in the range $650-900 \mathrm{cps} / \mathrm{MBq}$ of Tc-99 $\mathrm{m}$ for a 3 -cm-deep node. For a 3-cm-deep node with $1 \%$ uptake from a $40 \mathrm{MBq}$ injection of radiocolloid, with surgery at $2 \mathrm{~h}$ after injection, the surgeon will see a count rate of about $220 \mathrm{cps}$. The detected count rate falls rapidly with deeper nodes, and if this arises with lower percentage uptake and longer delay from surgery there may be a much lower count rate and more difficult localization. With experience, localization at low count rates is possible, but with greater variability, longer search time, and less confidence than at higher count rates.

The probe also picks up counts from sources that are not directly in front of the probe; gamma rays can penetrate through the side of the probe, and scattered gamma rays can enter the detector. Adequate shielding of the probe is therefore important, especially for OSCC due to close proximity of the injection site. The rejection of scatter is achieved by having a probe with a good "energy resolution," and with a narrow window.

\section{Probe Controls}

The probe analyzer has a number of settings affecting practical performance of the probe, and therefore ease of SLN localization. These include:

Energy Window Setting For Tc-99 m, the probe should be set to a fixed energy level of $140 \mathrm{keV}$, but the "width" setting is variable. The wider the window, the higher the sensitivity, but the greater the scatter detected. This is especially problematic close to the injection site, and the "high-sensitivity" (wider window) setting is therefore most useful for low-uptake nodes remote from the injection site.

Collimation Collimators may be removable, allowing great gain in sensitivity while sacrificing spatial resolution. Removal of the collimation can aid localization of lowuptake nodes remote from the injection site.

Additional Shielding Direct penetration of gamma rays through the side of the probe may be reduced by the use of lead plates to shield the injection site.
Integration Time Some systems allow averaging of the signal over time, reducing signal variability. Integration times $>1 \mathrm{~s}$ must be used with caution, since the user may be misled by the delay between the probe position and the corresponding sound signal.

Count Range The probe produces an audible change in pitch between a minimum and maximum cps range, e.g., 100-1000 cps. Counts outside the set range will all produce the same (low or high) pitch, necessitating adjustment. Inappropriate range setting can lead to failure of localization. Some probe systems can automatically adjust the pitch range for the detected counts, though this can be confusing when trying to get a sense of the absolute count at any point.

\section{Care of the Probe and Quality Assurance}

All radiation detectors must be checked and managed within a quality assurance (QA) program. Surgeons are advised to work closely with their nuclear medicine colleagues and medical physicists in setting up quality control (QC) procedures. Recommendations for testing are:

- On purchase, tests of performance are advised to give a reference value for sensitivity, energy resolution, and spatial resolution, and to form a baseline for day-to-day checks;

- Before each use, a basic check of function and performance with determination of count rate sensitivity to a long-lived radioactive source and its energy spectrum;

- Visual inspection for damage, particularly cables and connectors. All users must be advised that the probe detector is easily damaged by dropping;

- In the operating room, aiming the probe at the injection site can demonstrate that the probe is functioning; however, this is not a substitute for QC checks since even a 50\% loss in sensitivity would not have any effect on the general response to the injection site.

\section{Sterility}

The probe is placed into a sterile sheath, though this makes the probe tip larger. The skin surface may be scanned before sheathing, in which case the probe must be decontaminated by wiping with $70 \%$ alcohol or other supplier-recommended agent. When removing a sheath, care must be taken not to accidentally take off any removable collimator, since these are costly to replace. 


\section{Common Sources of Error or Problems}

1. Dropping the probe will usually cause it to stop functioning, so staff should be made aware of its fragility, and QA performed before each operating list. A spare probe can easily be interchanged. Damage to the cable and connectors are avoided by careful handling, aided by staff training.

2. Failure to replace a removable collimator considerably reduces spatial resolution.

3. Incorrect energy window setting may be caused by selecting the wrong isotope, or if the QA procedures are performed with a Co57 isotope and the procedure specifies that the energy window is set to Co57. To avoid this, perform all QA procedures on the Tc-99 m window, unless the window is unusually narrow, in which case attention must be paid to resetting the window after QA.

4. Good support from radiation experts in the nuclear medicine or medical physics department can be invaluable, particularly for routine QA, optimization, and purchase advice on performance. Awareness of the major pitfalls, both technical and patient-related variations, is essential.

\section{SURGICAL TECHNIQUE AND GAMMA PROBE DETECTION}

The following remarks are valid provided that (a) preoperative lymphoscintigraphy is carried out and (b) no cervical cutaneous flap will be raised.

\section{Procedure}

At the time of lymphoscintigraphy, SLNs are marked on the skin surface under scintigraphic guidance of a Co57labeled marker pen (held $90^{\circ}$ to the skin surface) and controlled transcutaneously by the nuclear medicine physician with a collimated, handheld gamma probe. Marking the skin with the head and neck in a position as similar as possible to the positioning during surgery may facilitate harvesting of the sentinel node.

Following radiotracer injection and LSG, patients undergo general anesthesia and preparation for operation. Optionally, blue dye may be injected at this time. Transoral excision of the primary tumor is performed either before or after sentinel node biopsy. Prior excision reduces the problem of shine-through from the injection site, but potentially limits the usefulness of blue dye due to rapid transit times through the lymphatics from the injection sites.

In the operating room, the gamma probe is covered with sterile latex and applied transcutaneously to confirm the accuracy of the skin markings, which may have changed due to changes in patient positioning between LSG and surgery. ${ }^{102}$ The theoretically optimal search pattern is to start closest to the injection site, with the probe perpendicular to the skin, using a raster pattern of $2-\mathrm{cm}$-spaced parallel lines at right angles to the direction of the injection site. A rise in activity is then confirmed by scanning in the other direction. Scanning should be no faster than a few $\mathrm{cm} / \mathrm{s}$. However, excessively slow scanning can lead to loss of information from the change in pitch as the probe passes over a hot node. The drop in counts as the probe is angulated whilst over a hot spot can confirm location.

\section{Location}

The lymphoscintigraphy images and skin markings guide the site of incision, which is placed along the relaxed skin tension lines and positioned to facilitate excision of the scar should subsequent neck dissection be required. Sentinel nodes are reached using one or more small incisions, and removed from levels $\mathrm{I}-\mathrm{V}$ according to the Robbins classification. ${ }^{103}$ Subplatysma skin flaps are not routinely raised for biopsy-only procedures. The gamma probe is introduced into the space along the plane of dissection and angled in various directions to guide the surgeon to the sentinel node, which is then excised. Sentinel nodes in the jugular chain are found close to the internal jugular vein and those in level I will usually be found in the submandibular triangle. If blue dye is used, blue-stained lymphatics may be followed to the sentinel nodes, which may be hot, blue or both. The anatomical location of the sentinel nodes should be noted, as should its color and radioactivity ex vivo in the operating theatre because both blue dye and radioactivity will dissipate before the pathological examination. In order to avoid potential confusion, surgeons and histopathologists should agree beforehand on the exact nomenclature used for labeling sentinel nodes and drainage basins. Following excision of SLNs, repeated readings are taken of the excision bed to ensure that there are no adjacent hot nodes that also need to be removed. ${ }^{36}$

\section{Selection of Nodes}

In OSCC, multiple SLNs are usually present, with reported mean numbers of 1.3 to 4 (range $1-11$ ). ${ }^{36}$ Preoperative LSG may underestimate the number of SLNs, especially when multiple SLNs are in close proximity. ${ }^{88,104}$ However, the numerous other advantages of preoperative LSG counter the suggestion that it may safely be omitted from the procedure. ${ }^{88}$ Careful consideration of inactive lymph nodes in the immediate vicinity of SLNs is imperative. Although nonsentinel nodes should not be excised, there may be a scenario where closely adjacent nodes are 
almost completely excised while dissecting out a sentinel node. Although this is uncommon, the nonsentinel node thus labeled may be sent for pathological examination. ${ }^{105}$

While preoperative imaging should detect the majority of grossly involved nodes, clinical staging remains imperfect. ${ }^{106}$ Any suspicious lymph nodes observed during SNB must be excised, even in the absence of radioactivity, since gross lymphatic involvement may block the flow of radiotracer to these nodes. See also the section on "Measured Radioactivity."

SLNs are ranked according to their respective tracer uptake ex vivo, with the SLN with the highest activity named SLN1, that with the second highest activity SLN2, and so forth. This does not mean that SLN2 is dependent on SLN1, as metastases may be found in any of the multiple SLNs independently. ${ }^{63,107-109}$

\section{Close Spatial Relation}

The problems of shine-through, whereby the high radioactivity levels from the injection site are detected from behind the tissue of interest, and scatter, in which the direction of radioactivity from the injection site is changed by the tissues and detected by the probe, are most prevalent in the submandibular and submental areas of the neck. ${ }^{36}$ For floor-ofmouth tumors, where the distance between primary site and SLN is smallest, this creates technical difficulty and results in lower SLN identification rates $(86 \%$, versus $96 \%$ for other OSCC subsites). ${ }^{28,110,111}$ Careful positioning of the gamma probe, judicious use of malleable lead shields, and excision of the primary tumor before SLN localization may all help to minimize these effects. ${ }^{34}$ Another option to improve identification in level I is to perform some initial dissection below the level of the marginal mandibular nerve, transecting the tissues down to the level of the mylohyoid muscle. In this manner, the lymph nodes are mobilized away from the oral cavity, and the gamma probe placed into the newly created tunnel and directed inferiorly away from the injection site. ${ }^{112}$

\section{Activity Counting}

Following excision, SLN radioactivity is confirmed ex vivo using the gamma probe, and must be above background activity to be classified as hot. ${ }^{74}$ The SLN should be placed on a surface away from the patient, or on the upturned probe tip (facing the ceiling). Anatomic location and radioactivity levels (cps) are recorded for all excised nodes. All radioactive nodes should be considered SLNs because, while there exists some confusion over the exact definition of a SLN, it is best to err on the side of patient safety. ${ }^{107}$ The lymphatic basin should be rechecked for reduced radioactivity after SLN excision. ${ }^{113}$ Bed counts in the neck after removal of SLN almost never exceed 8-10 cps (with the head of the probe slightly turned away from the injection site).

\section{Risk}

Sentinel node biopsy is not without risks, and injuries to the facial and spinal accessory nerves are possible through minimal exposure. Although complications rates of less than $1 \%$ are reported, the risk of injury to these nerves via minimal-access incisions is theoretically higher during SNB as compared with neck dissection. Similarly, neck dissection following positive SNB represents re-exploration in a recently operated field, and carries with it the higher risks of nerve or vessel damage. This reinforces the need for minimal tissue injury during the initial SNB procedure. ${ }^{112}$

\section{Experience}

It is clear that experience is needed before a surgeon starts performing sentinel node biopsy, as it carries a steep learning curve. This has led to the recommendation of completion of at least ten SNB-assisted elective neck dissections before the procedure is performed alone. ${ }^{38}$ In addition, it is necessary for practitioners of SNB to understand the theoretical aspects, including handling of radioactivity and optimal use of gamma probes.

\section{MEASURED RADIOACTIVITY (CPS)}

The role of measured cps during gamma probe detection is unclear. Because of the narrow anatomic relationships, defining a lower cutoff point for SLNs is practically impossible. It has been suggested that the number of harvested SLNs may be limited to the three nodes with the highest absolute cps, or the highest ratio of ex vivo nodeto-background activity (as for early studies in melanoma), in order to reduce surgical morbidity. ${ }^{25,88,114-118}$

For correct staging, at least the three nodes with the highest activity should be excised as SLNs, and all positive sentinels are detected within the first five nodes of highest activity in each patient. ${ }^{88,105,114}$ More than five SLNs are very rare, with three-quarters of patients having $\leq 3$ SLNs. For safety's sake, all radioactive nodes should be excised. ${ }^{69,105}$

In a study investigating the role of radioactivity in SNB, Kovacs et al. found no significant difference in absolute cps between positive and negative SLNs (medians of 157 and 235 cps, respectively), and the positive SLN need not have the highest tracer accumulation (range 13-4,716 cps). ${ }^{36,105}$ Activity in SLNs was not found to correlate with administered dose (in MBq), and the highest activity was found in level II. The authors reported that in each patient there was one SLN with a significantly higher cps rate than the remaining active nodes, and this node could be found in all levels. 
Following SLN excision, the remaining lymphatic basin is searched for residual radioactive nodes by means of an in situ survey measurement. A count rate less than one-tenth of the excised node with the lowest radioactivity is considered indicative that all SLNs have been identified and removed. In some centers, lymph nodes with count rates of less than one-tenth of the "hottest" excised node are not removed. This practice is based on the results of the large Sunbelt Melanoma trial, demonstrating a low failure rate of 2\%. ${ }^{119}$ However, no similar data have yet been reported for SCC.

The time from injection has also been found not to affect the relative counts between SLNs, or if it does, it affects the results only in case of very large time spans of $>14 \mathrm{~h}$, depending on the half-life of the tracer used. ${ }^{120,121}$ It is important, however, that the time span between injection and surgery is consistent for a given study population.

As a result, the absolute radioactivity counts are less important than relative levels between the excised nodes in the context of SNB. Similarly, absolute radioactivity counts cannot be compared between centers due to differences in protocol.

\section{PATHOLOGY EVALUATION OF SENTINEL NODE}

In OSCC, SNB has been examined only in the context of relatively small observational cohort studies, and the pathology protocols have typically been designed to detect micrometastases (MMs) and isolated tumor cells (ITCs) with high sensitivity. At present, the significance of finding MMs and ITCs is unknown in OSCC. The grade of evidence is currently at level III, as described in the SIGN methodology for clinical guidelines. ${ }^{122}$ Several large-scale validation studies (ACOSOG and the University of Miami, SENT, the Danish national group, and the Brazilian head and neck group) are currently underway. ${ }^{112,123-126}$

\section{Histological Definitions}

The present International Union against Cancer (UICC) definitions are shown in Table $1 .^{31}$ Whilst these definitions have been largely accepted, little information is available regarding the evidence on which they were based. The relationship of these definitions to tumor-node-metastasis (TNM) coding is demonstrated in Table 2.

One element which is clearly subjective in nature is the assessment of cell viability, as the significance of individual cytokeratin-positive "nonviable cells" is difficult to establish. Various terms have been employed for these cells, including "mummified cells" or thanatosomes. ${ }^{127}$ The present authors' practice (K.H., P.S.) is to include such elements in the morphological description, with careful correlation to the adjacent hematoxylin and eosin (H\&E)stained section. Features which may be useful include the lack of a nucleus, but the biological potential of these cells is as yet unknown.

In addition, the presence of cells in the lymphatic plexus should always be recorded. Whilst their significance is unknown, it appears that they do not represent extracapsular extension of tumor.

\section{Protocol}

A well-defined, written, standard operating procedure should be established between the surgical team and the reporting pathology laboratory. This should include how the specimen should be delivered to the laboratory, and outline the supporting documentation which accompanies it and appropriate elements of radiological protection practice. Other important elements may include agreed turnaround times and the manner in which the results are to be reported. An overview of the proposed pathologic evaluation protocol is presented in Fig. 3.

\section{Gross Sectioning}

The node or nodal basin should be fixed in $10 \%$ neutral buffered formalin (or equivalent) for $24 \mathrm{~h}$, as per standard laboratory practice. The nodes are described macroscopically, including dimensions, and excess fat is carefully trimmed away. Nodes less than $2 \mathrm{~mm}$ (longest dimension) should be processed whole, while nodes $2-5 \mathrm{~mm}$ should be cut through the hilum or longest pole-to-pole diameter, and both halves processed en face. Nodes greater than $5 \mathrm{~mm}$ should be cut into 2-mm slices, longest pole to pole, with processing of all slices en face.

\section{Step Sectioning}

A routine $H \& E$ section is prepared, and metastatic disease reported if present. If negative, six exact serial sections are mounted, and separately numbered 1-6. Next, $150 \mu \mathrm{m}$ material is discarded, or retained for research,

TABLE 1 UICC classification of micrometastases (MM) and isolated tumor cells (ITC)

\begin{tabular}{ll}
\hline Definition & Criteria \\
\hline Metastasis & $>2 \mathrm{~mm}$ \\
Micrometastasis & $\geq 0.2 \mathrm{~mm}$ and $\leq 2 \mathrm{~mm}$ \\
Isolated tumor cells & $<0.2 \mathrm{~mm}$ \\
& Single cells, small clusters \\
& No stromal reaction \\
& No contact with vessel wall \\
\hline
\end{tabular}


TABLE 2 Comparison of UICC and TNM classifications

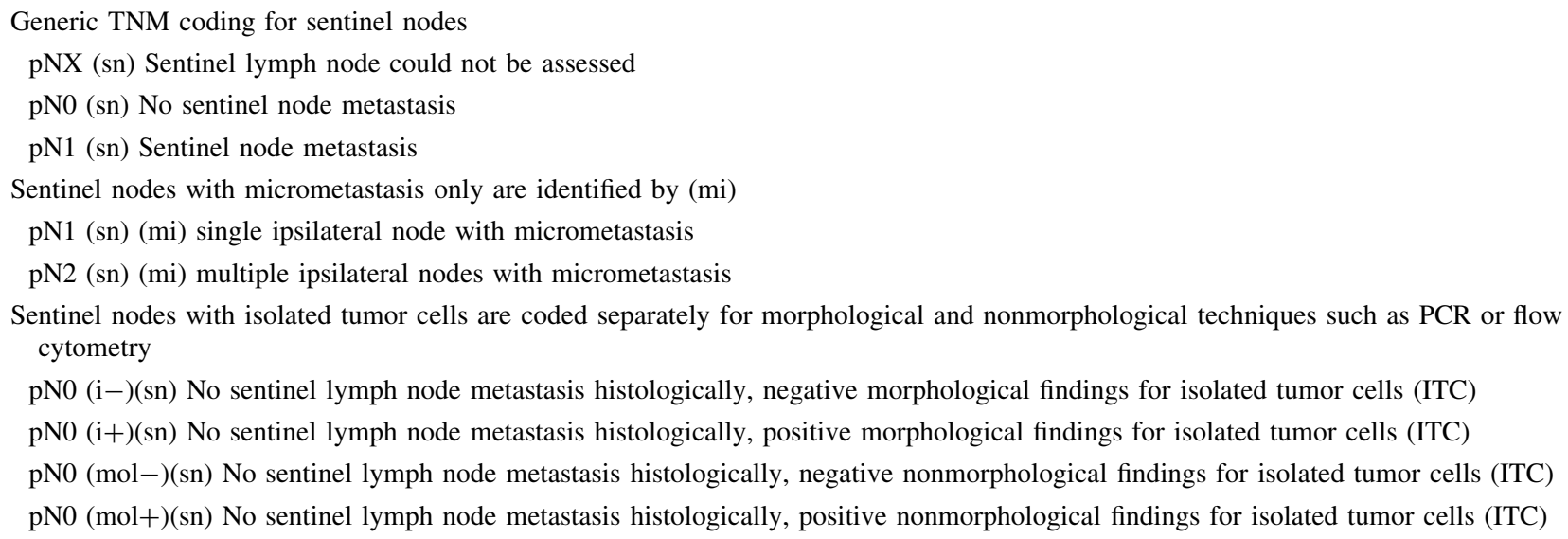

before a further six numbered serial sections are mounted. This pattern is continued throughout the entire block. All number 3 sections are stained by the $\mathrm{H} \& \mathrm{E}$ method, and metastatic disease reported if present. If negative or equivocal, immunocytochemistry (IHC) is performed on all number 2 sections using a pancytokeratin antibody (see below), and the slides examined for positivity. IHC-positive slides are compared with the adjacent section $3 \mathrm{H} \& \mathrm{E}$ slide. The remaining sections may be used if required.

Much of the published literature has utilized AE1/AE3 pancytokeratin antibody. However, concern has been expressed regarding the specificity of this anticytokeratin cocktail. Cross-reactivity is a problem seen with a number of pan-cytokeratin antibodies, and may mandate the use of more than one antibody in SNB protocols to clearly delineate MMs and ITCs from other elements in the node, such as dendritic cells and macrophages. However, presently it is reasonable to assume that any reputable commercially available pancytokeratin antibody (such as AE1/AE3 or MNF116) may be used. It is important to recognize artifacts, and any cytokeratin-positive components should always be compared with adjacent sections stained by hematoxylin and eosin (Figs. 4, 5, 6, 7, 8, 9).

\section{Microscopy}

Sections should be examined using a good-quality bright-field microscope and equivocal findings discussed with an experienced colleague. Where pancytokeratinpositive cells are present it is essential that adjacent sections are stained to allow morphological comparison.

\section{Report}

The side, number, and level of each node basin in the neck must be recorded. A diagram provided by the surgical team should be incorporated into the pathology record where possible.

The report must include details of the numbers of nodes found in each individual basin and which nodes were hot, blue, both or unlabeled. The dimensions of each node must be included and the macroscopic appearance of the gross and cut surfaces stated.

\section{- Macrometastasis}

- Note the largest dimension of the metastatic deposit in each node, and whether extracapsular spread is present or not.

\section{- Micrometastasis}

- Should be recorded, even in the presence of macrometastasis

- The largest dimension should be recorded

- Anatomical location within the node: capsular, subcapsular, parenchymal

- Unifocal or multifocal: it is often not possible to be confident of the exact numbers

- Presence of extracapsular spread. This is permitted if the deposit is peripherally located and is associated with a reactive stromal response

- Isolated tumor cells (ITC)

- If evident, should be recorded, even in the presence of macro- or micrometastasis

- If cohesive: the size of the largest deposit should be stated

- If dispersed: note the anatomical distribution

- Benign inclusions including nevus cells, salivary inclusions, and false-positive cytokeratin artifacts (e.g., dendritic cells or scattered nonviable anucleate cells) should be recorded. 


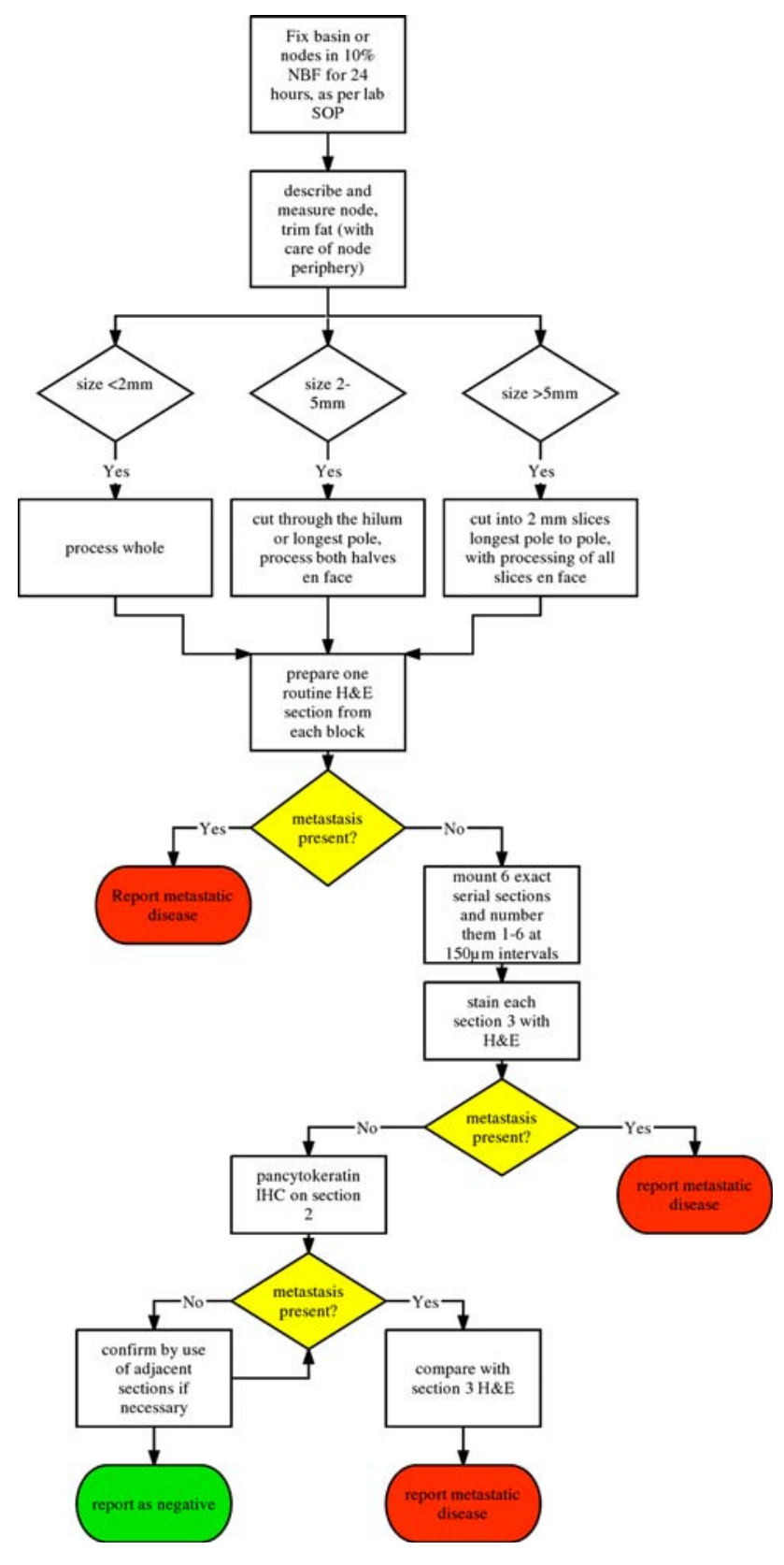

FIG. 3 Pathology evaluation of sentinel lymph nodes

The histopathological features of ITCs need careful description, as the UICC size cutoff by necessity encompasses small metastases which vary greatly in size and presumably in biological potential. Positive findings using nonmorphological methods in the absence of histologically proven metastasis are generally considered as ITCs.

\section{Other Methodologies}

Frozen Sections The use of frozen-section evaluation for SLNs has been described in a number of recent reports, and the results appear promising, with negative predictive

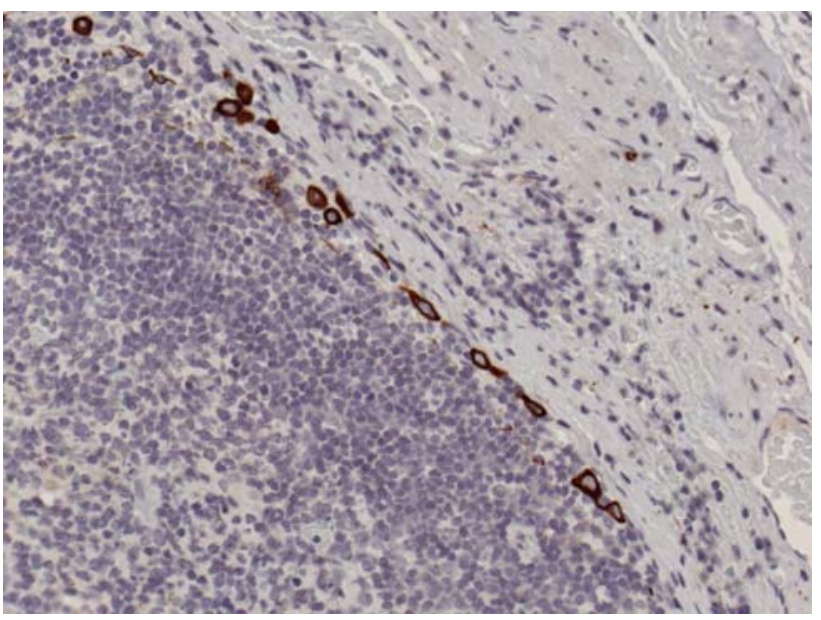

FIG. 4 Isolated tumor cells stained by AE1/AE3 in a sentinel lymph node

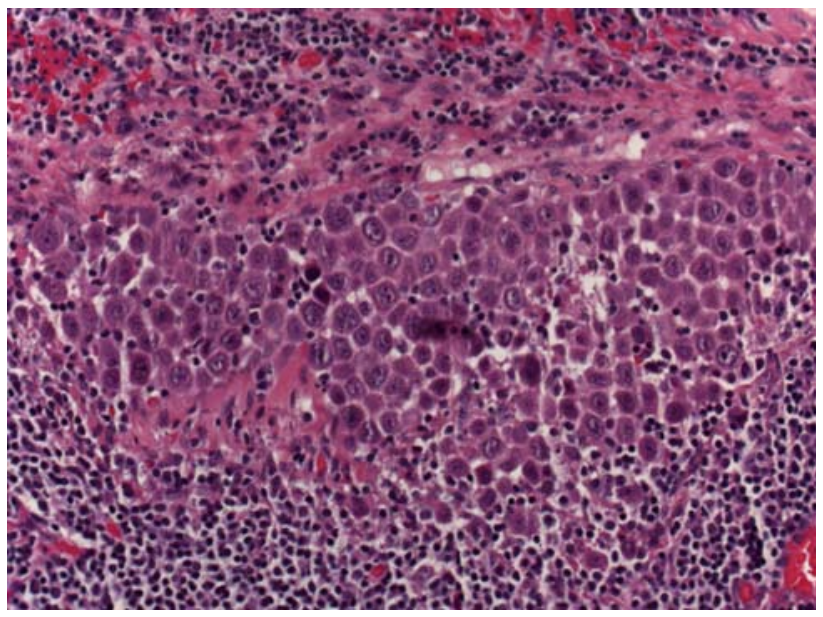

FIG. 5 A micrometastasis found in the seventh level of a sentinel node that was clear on initial sectioning. Viable nucleated squamous cells are present in a cohesive group. Section quality is suboptimal and recutting is not possible

values ranging from $83 \%$ to $99 \%{ }^{64,128,129}$ These results are in contrast to an earlier report by Civantos et al., who described poor sensitivity of frozen section compared with step-serial sectioning in a series of 43 oral cancer patients. ${ }^{130}$ The main advantage of the technique is that it may allow a majority of patients to undergo a single-stage procedure. While the use of frozen section is advocated by some authors, it has not yet gained universal acceptance.

\section{Imprint Cytology}

The use of imprint cytology in conjunction with frozen sections in the assessment of SLNs has been described in other tumors such as breast adenocarcinoma. One study in OSCC based on 30 cases demonstrated high sensitivity and specificity, though a recent study showed frozen section to 


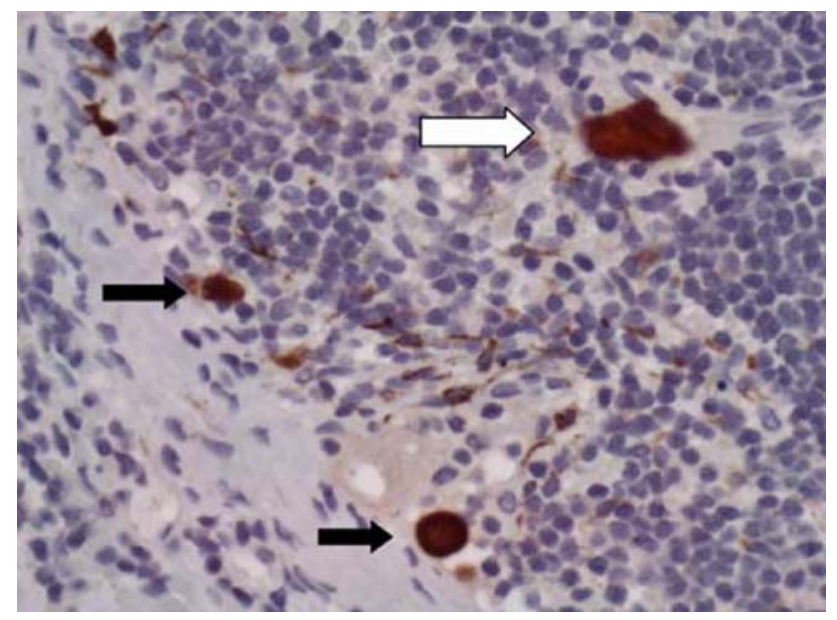

FIG. 6 Cytokeratin-positive cells in a sentinel node stained by CKC pan cytokeratin. The white arrow shows a contaminant squame (this can be ascertained by the geometric outline, lack of nucleus, and by focusing at high power). The black arrows show nonnucleated individual tumor cells, and dendritic cells can be seen in the background

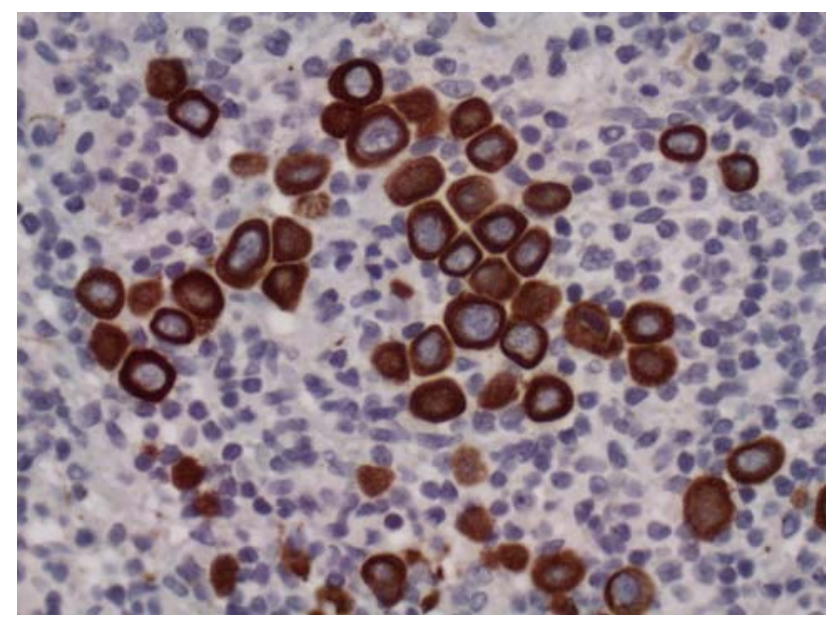

FIG. 7 A group of nucleated isolated tumor cells stained by AE1/ AE3 in a sentinel node

be a more accurate method of intraoperative diagnosis. ${ }^{128,131}$ Imprint cytology has an advantage over frozen section in that no tissue is lost in the generation of the sample, however much larger studies are required before considering adoption into the protocol.

Reverse-Transcriptase Polymerase Chain Reaction (RT$P C R)$ Methods with increased sensitivity, such as cytokeratin RT-PCR, have been suggested. The small number of studies published demonstrate expression of cytokeratins in nodes which were metastasis negative on initial assessment. However, only a proportion of the nodes demonstrated metastases on serial sectioning. ${ }^{132,133}$ The clinical role of these methods in the future remains

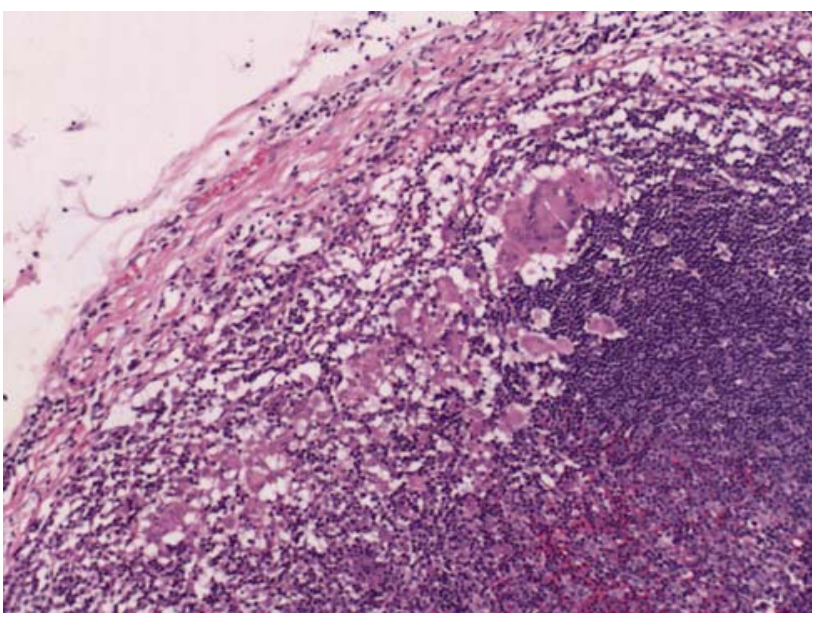

FIG. 8 Multinucleated and mononuclear macrophages revealed by the detailed protocol in a sentinel node that was clear in the first sections. These were suspicious for ITCs within the island

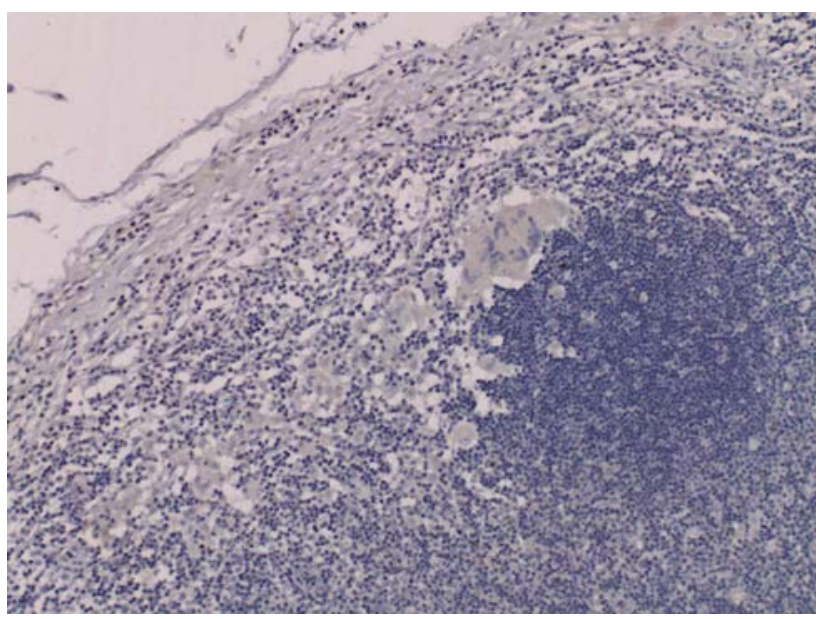

FIG. 9 Adjacent field to Fig. 5 stained by AE1/AE3, showing absence of tumor cells

uncertain given the ongoing concerns regarding their specificity together with the associated medicolegal problems, given that significant tissue must be used which has not been assessed histopathologically.

\section{Burden of Work}

The authors recognize that, on average, 2.5 sentinel node basins are yielded per neck side. The protocol above may produce up to 12 levels per node. If three nodes are present in each basin there could be 180 slides to examine. On the other hand, the majority of sentinel nodes are small and the nodes from a single basin can often be grouped into one cassette (using ink to identify "hot" and "blue" nodes), saving laboratory time and effort. In addition, the described protocol has the ability to detect all MMs. 
According to Cochran's principle, metastatic deposits tend to cluster in the plane of the hilum, and some authors argue the case for examination of bisected sentinel nodes at three or six levels only. ${ }^{134}$ Although such a protocol can theoretically miss a MM, it may turn out that no useful information is added by leveling through the block beyond six levels. ${ }^{135}$ However, several studies report that additional sentinel nodes are upstaged by step-serial sectioning with cytokeratin immunohistochemistry, compared with H\&E only. ${ }^{82}$

\section{OUTCOME ANALYSIS}

The success of this multidisciplinary staging technique depends on good communication between all of the individual components; imaging, surgery, and histopathology. The multidisciplinary team (MDT) setting should be utilized for the discussion of every patient, and regular audit of patient outcomes against published data should be carried out. SLNs should be successfully located and harvested in $>90 \%$ patients. ${ }^{28}$ The accuracy of the technique can be assessed by the proportions of patients whose SLN contain metastases, which should match that of END (20-30\%, depending on patient population and tumor size). ${ }^{136}$ Lastly, the rate of false negatives (SLN-negative patients who develop early recurrent disease) should be $<5 \%{ }^{137}$

Further studies are required to determine the full clinical significance of micrometastasis and individual tumor cells in OSCC. The biological potential of the tumor cells may vary with differing types of tumors, and clinical decisions currently have to be made on the basis of grade, stage, and margin status of the primary lesion as well as on microscopic findings in the sentinel node. ${ }^{138,139}$ The optimum protocol will hopefully emerge from the large-scale trials and studies currently in progress. ${ }^{110,123-126}$ One of the major aims of SNB in OSCC is to achieve better staging, and thorough pathological examination of SLNs remains the standard.

\section{SUMMARY}

Successful application of the SNB technique is dependent on good communication between all members of the multidisciplinary team, and this joint guideline represents an extension of that approach. Sentinel node biopsy provides an additional tool for staging patients with early OSCC. However, it is not without limitations, and all practitioners of SNB must be aware of these. It is hoped that this document will serve as a reference outlining the optimal practice for the provision of SNB in patients with OSCC, based on the best currently available evidence. As such, the use of the above protocol is recommended until further data, in the form of results from currently underway large prospective studies, become available.

ACKNOWLEDGEMENT The authors would like to thank the European Association of Nuclear Medicine's Physics, Dosimetry, and Radiopharmacy Committees for their assistance in production of this manuscript.

OPEN ACCESS This article is distributed under the terms of the Creative Commons Attribution Noncommercial License which permits any noncommercial use, distribution, and reproduction in any medium, provided the original author(s) and source are credited.

\section{REFERENCES}

1. Parkin DM, Bray F, Ferlay J, et al. Global cancer statistics 2002. CA Cancer J Clin. 2005;55:74-108.

2. Pitman KT, Johnson JT,Myers EN. Effectiveness of selective neck dissection for management of the clinically negative neck. Arch Otolaryngol Head Neck Surg. 1997;123:917-22.

3. Shah JP, Candela FC, Poddar AK. The patterns of cervical lymph node metastases from squamous carcinoma of the oral cavity. Cancer. 1990;66:109-13.

4. Spiro JD, Spiro RH, Shah JP, Sessions RB, Strong EW. Critical assessment of supraomohyoid dissection. Am J Surg. 1988; 156:286-9.

5. Gourin CG, Conger BT, Porubsky ES, Sheils WC, Bilodeau PA, Coleman TA. The effect of occult nodal metastases on survival and regional control in patients with head and neck squamous cell carcinoma. Laryngoscope. 2008;118:1191-4.

6. Don DM, Anzai Y, Lufkin RB, Fu YS, Calcaterra TC. Evaluation of cervical lymph node metastasis in squamous carcinoma of the head and neck. Laryngoscope. 1995;105:669-74.

7. Leemans CR, Tiwari R, Van der Waal I, Karim ABMF, Nauta JP, Snow GB. The efficacy of comprehensive neck dissection with or without postoperative radiotherapy in nodal metastases of squamous cell carcinoma of the upper respiratory and digestive tracts. Laryngoscope. 1990;100:1194-8.

8. Ambrosch P, Kron M, Fischer G, Brinck U. Micrometastases in carcinoma of the upper aerodigestive tract: detection, risk of metastasizing, and prognostic value of depth of invasion. Head Neck. 1995;17:473-9.

9. Kane SV, Gupta M, Kakade AC, D' Cruz A. Depth of invasion is the most significant histological predictor of subclinical cervical lymph node metastasis in early squamous carcinomas of the oral cavity. Eur J Surg Oncol. 2006;32:795-803.

10. Pimenta Amaral TM, Da Silva Freire AR, Carvalho AL, Pinto CA, Kowalski LP. Predictive factors of occult metastasis and prognosis of clinical stages I and II squamous cell carcinoma of the tongue and floor of the mouth. Oral Oncol. 2004;40:780-6.

11. Yamamoto E, Miyakawa A, Kohama G. Mode of invasion and lymph node metastasis in squamous cell carcinoma of the oral cavity. Head Neck Surg. 1984;6:938-47.

12. Alkureishi LWT, Ross GL, Shoaib T, Soutar DS, Robertson AG, Sorensen JA, et al. Does tumor depth affect nodal upstaging in squamous cell carcinoma of the head and neck. Laryngoscope. 2008;118:629-34.

13. Goerkem M, Braun J, Stoeckli SJ. Evaluation of clinical and histomorphological parameters as potential predictors of occult metastases in sentinel lymph nodes of early squamous cell carcinomas of the oral cavity (in press). 
14. Byers RM. Modified neck dissection: a study of 967 cases from 1970 to 1980. Am J Surg. 1985;150:414-21.

15. Byers RM, Wolf PF, Ballantyne AJ. Rationale for elective modified neck dissection. Head Neck Surg. 1988;10:160-7.

16. Shah JP. Cervical lymph node metastases-diagnostic, therapeutic and prognostic implications. Oncology. 1990;4:61-9.

17. Shah JP, Andersen PE. Evolving role of modifications in neck dissection for oral squamous carcinoma. Br J Oral Maxillofac Surg. 1995;33:3-8.

18. Brazilian Head and Neck Cancer StudyGroup. Results of a prospective trial on elective modified radical classical versus supraomohyoid neck dissection in the management of oral squamous carcinoma. Am J Surg. 1998;176:422-6.

19. Pitman KT. Rationale for elective neck dissection. Am J Otolaryngol. 2000;21:31-7.

20. Cheng A, Schmidt BL. Management of the N0 neck in oral squamous cell carcinoma. Oral Maxillofac Surg Clin North Am. 2008;20:477-97.

21. Lindberg R. Distribution of cervical lymph node metastases from squamous cell carcinoma of the upper respiratory and digestive tracts. Cancer. 1972;29:1446-9.

22. Byers RM, Clayman GL, McGill D, Andrews T, Kare RP, Roberts DB, Goepfert H. Selective neck dissections for squamous carcinoma of the upper aerodigestive tract: patterns of regional failure. Head Neck. 1999;21:499-505.

23. Morton DL, Wen DR, Wong JH, Economou JS, Cagle LA, Storm FK, Foshag LJ, Cochran AJ. Technical details of intraoperative lymphatic mapping for early stage melanoma. Arch Surg. 1992;127:392-9.

24. Cabanas RM. An approach for the treatment of penile carcinoma. Cancer. 1977;39:456-66.

25. Alex JC, Weaver DL, Fairbank JT, Rankin BS, Krag DN. Gamma-probe-guided lymph node localization in malignant melanoma. Surg Oncol. 1993;2:303-8.

26. Morton DL, Wen DR, Cochran AJ. Management of earlystage melanoma by intraoperative lymphatic mapping and selective lymphadenectomy. Surg Oncol Clin North Am. 1992;1247-9.

27. Krag DN. Surgical resection and radiolocalization of the SLN in breast cancer using a gamma probe. Surg Oncol. 1993;2:335-40.

28. Ross GL, Soutar DS, MacDonald G, et al. Sentinel node biopsy in head and neck cancer: preliminary results of a multicenter trial. Ann Surg Oncol. 2004;11:690-6.

29. Stoeckli SJ, Steinert H, Pfaltz M, Schmid S. Sentinel lymph node evaluation in squamous cell carcinoma of the head and neck. Otolaryngol Head Neck Surg. 2001;125:221-6.

30. Kovács AF, Döbert N, Gaa J, Menzel C, Bitter K. Positron emission tomography in combination with sentinel node biopsy reduces the rate of elective neck dissections in the treatment of oral and oropharyngeal cancer. J Clin Oncol. 2004;22: 3973-80.

31. Sobin LH, Wittekind Ch (eds) TNM classification of malignant tumours, 6th ed. New York: Wiley; 2002.

32. Hornstra MT, Alkureishi LWT, Ross GL, Shoaib T, Soutar DS. Predictive factors for failure to identify sentinel nodes in head and neck squamous cell carcinoma. Head Neck. 2008;30:85862.

33. Alex JC, Krag DN. The gamma-probe-guided resection of radiolabeled primary lymph nodes. Surg Oncol Clin North Am. 1996;5:33-41.

34. Shoaib T, Soutar DS, Prosser JE, et al. A suggested method for sentinel node biopsy in squamous cell carcinoma of the head and neck. Head Neck. 1999;21:728-33.

35. Kovács AF, Stefenelli U, Seitz O, Middendorp M, Diener J, Sader R, et al. Positive sentinel lymph nodes are a negative prognostic factor for survival in T1-2 oral/oropharyngeal cancer- a long-term study on 103 patients. Ann Surg Oncol. 2009;16:233-9.

36. Werner JA, Dünne AA, Ramaswamy A, Dalchow C, Behr T, Moll R, et al. The sentinel node concept in head and neck cancer: solution for the controversies in the N0 neck? Head Neck. 2004;26:603-11.

37. Ross GL, Soutar DS, Shoaib T, Camilleri IG, MacDonald DG, Robertson AG, et al. The ability of lymphoscintigraphy to direct sentinel node biopsy in the clinically N0 neck for patients with head and neck squamous cell carcinoma. Br J Radiol. 2002;75:950-8.

38. Ross GL, Shoaib T, Soutar DS, MacDonald DG, Camilleri IG, Bessent RG, et al. The first international conference on sentinel node biopsy in mucosal head and neck cancer and adoption of a multicenter trial protocol. Ann Surg Oncol. 2002;9:406-10.

39. Stoeckli SJ, Pfaltz M, Ross GL, Steiner HC, MacDonald DG, Wittekind C, Soutar D. The second international conference on sentinel node biopsy in mucosal head and neck cancer. Ann Surg Oncol. 2005;12:919-24.

40. Wilhelm AJ, Mijnhout GS, Franssen EJF. Radiopharmaceuticals in sentinel lymph-node detection-an overview. Eur $J$ Nucl Med. 1999;26:S36-42.

41. Jimenez IR, Roca M, Vega E, García ML, Benitez A, Bajén M, et al. Particle sizes of colloids to be used in sentinel lymph node radiolocalization. Nucl Med Commun. 2008;29:166-72.

42. Kovács AF, Döbert N, Walendzik H, Zaplatnikov K, Landes CA. The diagnostic role of radioactivity in sentinel nodes in oral and oropharyngeal cancer. Cancer Biother Radiopharm. 2006;21:535-43.

43. Thomsen JB, Sørensen JA, Grupe P, Krogdahl A. Sentinel lymph node biopsy in oral cancer: validation of technique and clinical implications of added oblique planar lymphoscintigraphy and/or tomography. Acta Radiol. 2005;46:569-75.

44. GE Healthcare, Milan, Italy. Nanocoll ${ }^{\circledR}$ technical leaflet; 2009.

45. Millar AM, O'Brien LM, Beattie LA, Craig F, McDade J. Validation of an extended shelf-life for Tc-99 m albumin nanocolloid injection. Nucl Med Commun. 2007;28:A15.

46. Burton DA, Cashman JN. Allergic reaction to nanocolloid during lymphoscintigraphy for sentinel node biopsy. Br J Anaesth. 2002;89:105.

47. Chicken DW, Mansouri R, Ell PJ, Keshtgar MR. Allergy to technetium-labeled nanocolloidal albumin for sentinel node identification. Ann R Coll Surg Engl. 2007;89:W12-13.

48. Keller B, Yawalkar N, Pichler C, Braathen LR, Hunger RE. Hypersensitivity reaction against patent blue during sentinel lymph node removal in three melanoma patients. Am J Surg. 2007;193:122-4.

49. Koizumi M, Nomura E, Yamada Y, Takiguchi T, Tanaka K, Yoshimoto M, et al. Sentinel node detection using Tc-99 mrhenium sulphide colloid in breast cancer patients: evaluation of 1 day and 2 day protocols, and a dose-finding study. Nucl Med Commun. 2003;24:663-70.

50. Chakera AH, Hesse B, Burak Z, Ballinger JR, Britten A, Caracò $\mathrm{C}$, et al. EANM-EORTC recommendations for sentinel node diagnostics in melanoma. Eur J Nucl Med Mol Imaging. accepted for publication (2009).

51. Buscombe J, Paganelli G, Burak ZE, Waddington W, Maublant J, Prats E, et al. Sentinel node in breast cancer procedural guidelines. Eur J Nucl Med Mol Imaging. 2007;12:2154-9.

52. Waddington WA, Keshtgar MRS, Taylor I, Lakhani SR, Short MD, Ell PJ. Radiation safety of the sentinel node technique in breast cancer. Eur J Nucl Med. 2000;27:377-91.

53. Pandit-Tskar NN, Dauer LT, Montgomery L, St. Germain J, Zanzonico PB, Divgi CR. Organ and fetal absorbed dose estimates from Tc-99 m- sulfur colloid lymphoscintigraphy and sentinel node localization in breast cancer patients. $J$ Nucl Med. 2006;47:1202-8. 
54. International Commission on Radiological Protection, ICRP Publication 54: individual monitoring for intakes of radionuclides by workers: design and interpretation. Annals of the ICRP, Volume 19/1-3, ISBN-13: 9780080356006, ISBN-10: 008035600-1, 1989.

55. Sera T, Mohos G, Papos M, et al. Sentinel node detection in malignant melanoma patients: radiation safety considerations. Dermatol Surg. 2003;29:141-5.

56. Stratmann SL, McCarthy TM, Kuhn JA. Radiation safety with breast sentinel node biopsy. Am J Surg. 1999;25:196-202.

57. Klausen TL, Chakera AH, Friis E, Rank F, Hesse B, Holm S. Radiation doses to staff involved in sentinel node operations for breast cancer. Clin Physiol Funct Imaging. 2005;25:196-202.

58. Nejc D, Wrzesien M, Piekarski J, et al. Sentinel node biopsy in skin melanoma patients - measurements of absorbed doses of radiation to the hands of medical staff. J Surg Oncol. 2006;93: 355-61.

59. Glass EC, Basinski JE, Krashne DL, Guiliano AE. Radiation safety considerations for sentinel node techniques. Ann Surg Oncol. 1996;6:10-1.

60. Radiation Safety Practice in Nuclear Medicine. In: Austria editor, IAEA nuclear medicine resources manual; 2006. p. 509-21.

61. Nugent N, Hill AD, Casey M, et al. Safety guidelines for radiolocalised sentinel node resection. Ir J Med Sci. 2001;170:236-8.

62. Chiesa F, Mauri S, Grana C, Tradati N, Calabrese L, Ansarin M, et al. Is there a role for sentinel node biopsy in early N0 tongue tumors? Surgery. 2000;128:16-21.

63. Shoaib T, Soutar DS, MacDonald DG, Camilleri IG, Dunaway DJ, Gray HW, et al. The accuracy of head and neck carcinoma sentinel lymph node biopsy in the clinically N0 neck. Cancer. 2001;91:2077-83.

64. Stoeckli SJ. Sentinel node biopsy for oral and oropharyngeal squamous cell carcinoma of the head and neck. Laryngoscope. 2007;117:1539-51.

65. De Cicco C, Trifirò G, Calabrese L, Bruschini R, Ferrari ME, Travaini LL, et al. Lymphatic mapping to tailor selective lymphadenectomy in cN0 tongue carcinoma: beyond the sentinel node concept. Eur J Nucl Med Mol Imaging. 2006;33:900-5.

66. Modi S, Stanton AW, Mortimer PS, Levick JR. Clinical assessment of human lymph flow using removal rate constants of interstitial macromolecules: a critical review of lymphoscintigraphy. Lymphat Res Biol. 2007;5:183-202.

67. Uren RF, Howman-Giles RB, Chung D, Thompson JF. Role of lymphoscintigraphy for selective sentinel lymphadenectomy. Cancer Treat Res. 2005;127:15-38.

68. Glass EC, Essner R, Morton DL. Kinetics of three lymphoscintigraphic agents in patients with cutaneous melanoma. $J$ Nucl Med. 1998;39:1185-90.

69. Bilde A, von BC, Mortensen J, Marving J, Hamilton TM, Kirkegaard J, et al. The role of SPECT-CT in the lymphoscintigraphic identification of sentinel nodes in patients with oral cancer. Acta Otolaryngol. 2006;126:1096-103.

70. IEC/TR 61948-2 Ed. 1.0 English. Nuclear medicine instrumentation - Routine tests - Part 2: scintillation cameras and single photon emission computed tomography imaging. 13-2-2001. Geneva: International Electrotechnical Commission. Ref Type: Report.

71. Tartaglione G, Vigili MG, Rahimi S, Celebrini A, Pagan M, Lauro L, et al. The impact of superficial injections of radiocolloids and dynamic lymphoscintigraphy on sentinel node identification in oral cavity cancer: a same-day protocol. $\mathrm{Nucl}$ Med Commun. 2008;29:318-22.

72. Wagner A, Schicho K, Glaser C, Zettinig G, Yerit K, Lang S, et al. SPECT-CT for topographic mapping of sentinel lymph nodes prior to gamma probe-guided biopsy in head and neck squamous cell carcinoma. J Craniomaxillofac Surg. 2004;32:343-9.
73. Khafif A, Schneebaum S, Fliss DM, Lerman H, Metser U, BenYosef R, et al. Lymphoscintigraphy for sentinel node mapping using a hybrid single photon emission CT (SPECT)/CT system in oral cavity squamous cell carcinoma. Head Neck. 2006;28: 874-9.

74. Thomsen JB, Sørensen JA, Grupe P, Krogdahl A. Sentinel lymph node biopsy in oral cancer: validation of technique and clinical implications of added oblique planar lymphoscintigraphy and/or tomography. Acta Radiol. 2005;46:569-75.

75. Haerle SK, Hany TF, Strobel K, Sidler D, Stoeckli SJ. Is there an additional value of SPECT/CT over lymphoscintigraphy for sentinel node mapping in oral/oropharyngeal squamous cell carcinoma? Ann Surg Oncol. (in press).

76. Keski-Santti H, Matzke S, Kauppinen T, Tornwall J, Atula T. Sentinel lymph node mapping using SPECT-CT fusion imaging in patients with oral cavity squamous cell carcinoma. Eur Arch Otorhinolaryngol. 2006;263:1008-12.

77. Lopez R, Payoux P, Gantet P, Esquerre JP, Boutault F, Paoli JR. Multimodal image registration for localization of sentinel nodes in head and neck squamous cell carcinoma. J Oral Maxillofac Surg. 2004;62:1497-1504.

78. Uren RF, Howman-Giles RB, Shaw HM, Thompson JF, McCarthy WH. Lymphoscintigraphy in high-risk melanoma of the trunk: predicting draining node groups, defining lymphatic channels and locating the sentinel node. J Nucl Med. 1993;34:1435-40.

79. Uren RF, Howman-Giles RB, Thompson JF, Roberts J, Bernard E. Variability of cutaneous lymphatic flow rates in melanoma patients. Melanoma Res. 1998;8:279-82.

80. Nieuwenhuis EJ, Pijpers R, Castelijns JA, Snow GB. Lymphoscintigraphic details of sentinel lymph node detection in 82 patients with squamous cell carcinoma of the oral cavity and oropharynx. Nucl Med Commun. 2003;24:651-6.

81. Even-Sapir E, Lerman H, Lievshitz G, Khafif A, Fliss DM, Schwartz A, et al. Lymphoscintigraphy for sentinel node mapping using a hybrid SPECT/CT system. J Nucl Med. 2003;44:1413-20.

82. Bilde A, von Buchwald C, Therkildsen MH, Mortensen J, Kirkegaard J, Charabi B, et al. Need for intensive histopathologic analysis to determine lymph node metastases when using sentinel node biopsy in oral cancer. Laryngoscope. 2008;118:408-14.

83. Werner JA, Dunne AA, Myers JN. Functional anatomy of the lymphatic drainage system of the upper aerodigestive tract and its role in metastasis of squamous cell carcinoma. Head Neck. 2003;25:322-32.

84. Frerich B, Forster M, Schiefke F, Wittekind C, Hemprich A, Sabri O. Sentinel lymph node biopsy in squamous cell carcinomas of the lips and the oral cavity-a single center experience. J Surg Oncol. 2007;95:97-105.

85. Alvarez J, Barbier L, Pijoan Jl, Martín JC, Romo L, Genolla J, et al. Diagnostic efficacy of sentinel node biopsy in oral squamous cell carcinoma. Cohort study and meta-analysis. Med Oral Patol Oral Cir Bucal. 2007;12:E235-43.

86. Shoaib T, Soutar DS, MacDonald DG, Gray HW, Ross GL. The nodal neck level of sentinel lymph nodes in mucosal head and neck cancer. Br J Plast Surg. 2005;58:790-4.

87. Gallegos-Hernandez JF, Hernandez-Hernandez DM, FloresDiaz R, Sierra-Santiesteban I, Pichardo-Romero P, Rias-Cebal$\operatorname{los} \mathrm{H}$, et al. The number of sentinel nodes identified as prognostic factor in oral epidermoid cancer. Oral Oncol. 2005;41:947-52.

88. Hoft S, Maune S, Muhle C, Brenner W, Czech N, Kampen WU, et al. Sentinel lymph-node biopsy in head and neck cancer. $B r J$ Cancer. 2004;91:124-8.

89. Kontio R, Leivo I, Leppanen E, Atula T. Sentinel lymph node biopsy in oral cavity squamous cell carcinoma without clinically evident metastasis. Head Neck. 2004;26:16-21. 
90. Mozzillo N, Chiesa F, Botti G, Caraco C, Lastoria S, Giugliano $\mathrm{G}$, et al. Sentinel node biopsy in head and neck cancer. Ann Surg Oncol. 2001;8:103S-5S.

91. Uren RF, Howman-Giles R, Thompson JF, McCarthy WH, Quinn MJ, Roberts JM, et al. Interval nodes: the forgotten sentinel nodes in patients with melanoma. Arch Surg. 2000;135:1168-72.

92. Klutmann S, et al. Lymphoscintigraphy in tumors of the head and neck using double tracer technique. J Nucl Med. 1999;40(5):776-82.

93. Warner $\mathbf{J}$, et al. Contamination problem with sentinel node localization procedure: a case study. J Nucl Med Technol. 2002;30:18-20.

94. Laasanen MS, et al. Localization of sentinel nodes in breast cancer: a novel method and device to help pen marking of active nodes during gamma camera imaging. Phys Med Biol. 2005;50:N49-54.

95. Scherer K, Studer W, Figueiredo V, Bircher AJ. Anaphylaxis to isosulfan blue and cross-reactivity to patent blue V: case report and review of the nomenclature of vital blue dyes. Ann Allergy Asthma Immunol. 2006;96:497-500.

96. The sentinel node in surgical oncology. Springer; 1999.

97. Lymphatic mapping and probe applications in oncology. Marcel Dekker; 2000.

98. Sentinel lymph node biopsy. Martin Dunitz; 2002.

99. Perkins AC, Britten AJ. Specification and performance of intraoperative gamma probes for sentinel node detection. Nucl Med Commun. 1999;20:309-15.

100. Tiourina T, Arends B, Huysmans D, Rutten H, Lemaire B, Muller S. Evaluation of surgical gamma probes for radioguided sentinel node localisation. Eur J Nucl Med. 1998;25:1224-31.

101. Britten AJ. A method to evaluate intra-operative gamma probes for sentinel lymph node localisation. Eur J Nucl Med. 1999;26:76-83.

102. Alex JC. The application of sentinel node radiolocalization to solid tumors of the head and neck: a 10-year experience. Laryngoscope. 2004;114:2-19.

103. Robbins KT, Medina JE, Wolfe GT, et al. Standardizing neck dissection terminology. Official Report of the Academy's Committee for Head and Neck Surgery and Oncology. Arch Otolaryngol Head Neck Surg. 1991;117:601-5.

104. Thomsen JB, Sorensen JA, Grupe P, et al. Staging N0 oral cancer: lymphoscintigraphy and conventional imaging. Acta Radiol. 2005;46:492-6.

105. Kovacs AF, Acker P, Berner U, Risse JH. Sentinel lymph node excision. Treatment method of the N0 neck in patients with oral and oropharyngeal carcinoma. HNO. 2001;49(8):646-53.

106. Alkureishi LW, Ross GL, MacDonald DG, Shoaib T, Gray H, Robertson G, et al. Sentinel node in head and neck cancer: use of size criterion to upstage the no neck in head and neck squamous cell carcinoma. Head Neck. 2007;29:95-103.

107. Nieweg OE, Tanis PJ, Kroon BB. The definition of a sentinel node. Ann Surg Oncol. 2001;8:538-41.

108. Werner JA, Dünne AA, Ramaswamy A, et al. Number and location of radiolabeled, intraoperatively identified sentinel nodes in 48 head and neck cancer patients with clinically staged N0 and N1 neck. Eur Arch Otorhinolaryngol. 2002;259:91-6.

109. Hyde NC, Prvulovich E, Newman L, et al. A new approach to pretreatment assessment of the N0 neck in oral squamous-cell carcinoma: the role of sentinel node biopsy and positron emission tomography. Oral Oncol. 2003;39:350-60.

110. Alkureishi LWT, Ross GL, Shoaib T, Soutar DS, Robertson AG, Sorensen JA, et al. Sentinel node biopsy in oral/oropharyngeal squamous cell cancer: five year follow-up. Presented at the American Head and Neck Society annual meeting in San Francisco, California, July 2008.
111. Civantos F, Zitsch R, Bared A. Sentinel node biopsy in oral squamous cell carcinoma. J Surg Oncol. 2007;96:330-6.

112. Civantos FJ, Werner JA, Bared A. Sentinel node biopsy in cancer of the oral cavity. Operative technique. Otolaryngology. $2005 ; 16: 275-85$.

113. Chikamatsu K, Kamada H, Ninomiya H, et al. A preliminary study on sentinel lymph node biopsy: feasibility and predictive ability in oral cavity cancer. Ann Nucl Med. 2004;18:257-62.

114. Werner JA, Dünne AA, Ramaswamy A, et al. Sentinel node detection in N0 cancer of the pharynx and larynx. Br J Cancer. 2002;87:711-5

115. Albertini JJ, Cruse CW, Rapaport D, et al. Intraoperative radiolympho-scintigraphy improves sentinel lymph node identification for patients with melanoma. Ann Surg. 1996;223:217-24.

116. Bostick P, Essner R, Sarantou T, et al. Intraoperative lymphatic mapping for early-stage melanoma of the head and neck. Am J Surg. 1997;174:536-9.

117. Brobeil A, Kamath D, Cruse CW, et al. The clinical relevance of sentinel lymph nodes identified with radiolymphoscintigraphy. J Fla Med Assoc. 1997;84:157-60.

118. Glass LF, Messina JL, Cruse W, et al. The use of intraoperative radiolymphoscintigraphy for sentinel lymph node biopsy in patients with malignant melanoma. Dermatol Surg. 1996;22:715-20.

119. McMasters KM, Noyes RD, Reintgen DS, et al. Sunbelt Melanoma Trial. Lessons learned from the Sunbelt Melanoma Trial. J Surg Oncol. 2004;86:212-23.

120. Carlson GW, Murray DR, Thourani V, et al. The definition of the sentinel lymph node in melanoma based on radioactive counts. Ann Surg Oncol. 2002;9:929-33.

121. Essner R, Bostick PJ, Glass EC, et al. Standardized probedirected sentinel node dissection in melanoma. Surgery. 2000;127:26-31.

122. Scottish Intercollegiate Guidelines Network 2008 SIGN 50: a guideline developer's handbook Chapter 7 ISBN 19781905813 254. http://www.sign.ac.uk/guidelines/fulltext/50/index.html.

123. Civantos FJ, Werner JA, Bared A. Sentinel node biopsy in cancer of the oral cavity. Oper Tech Otol-Head Neck Surg. 2005;16:275-85. American College of Surgeons Oncology Group trial Z0360.

124. Ross GL, on behalf of the Sentinel European Node Trial (SENT) Organising Committee. Sentinel node biopsy for squamous cell carcinoma of the oral cavity: preliminary results of the SENT trial. Presented at the annual meeting of the American Head and Neck Society (AHNS), San Francisco, July 2008.

125. Bilde A, von Buchwald C, Therkildsen MH, Mortensen J, Kirkegaard J, Charabi B, et al. Need for intensive histopathologic analysis to determine lymph node metastases when using sentinel node biopsy in oral cancer. Laryngoscope. 2008;118:408-14.

126. Chone CT, Magalhes RS, Etchehebere E, Camargo E, Altemani A, Crespo AN. Predictive value of sentinel node biopsy in head and neck cancer. Acta Otolaryngol. 2008;128:920-4.

127. Papadimitriou JC, Drachenberg CB, Brenner DS, Newkirk C, Trump BF, Silverberg SG. "Thanatosomes": a unifying morphogenetic concept for tumor hyaline globules related to apoptosis. Hum Pathol. 2000;31:1455-65.

128. Terada A, Hasegawa Y, Yatabe Y, Hyodo I, Ogawa T, Hanai N, et al. Intraoperative diagnosis of cancer metastasis in sentinel lymph node of oral cancer patients. Oral Oncol. 2008;44:83843.

129. Tschopp L, Nuyens M, Stauffer E, Krause T, Zbären P. The value of frozen section analysis of the sentinel lymph node in clinically NO squamous cell carcinoma of the oral cavity and oropharynx. Otolaryngol Head Neck Surg. 2005;132:99-102.

130. Civantos FJ, Moffat FI, Goodwin WJ. Lymphatic mapping and sentinel lymphadenectomy for 106 head and neck lesions: 
contrasts between oral cavity and cutaneous malignancy. Laryngoscope. 2006;16:1-15.

131. Asthana S, Deo SV, Shukla NK, Jain P, Anand M, Kumar R. Intraoperative neck staging using sentinel node biopsy and imprint cytology in oral cancer. Head Neck. 2003;25:368-72.

132. Garrel R, Dromard M, Costes V, et al. The diagnostic accuracy of reverse transcription-PCR quantification of cytokeratin mRNA in the detection of sentinel lymph node invasion in oral and oropharyngeal squamous cell carcinoma: a comparison with immunohistochemistry. Clin Cancer Res. 2006;12:2498-505.

133. Shores CG, Yin X, Funkhouser W, Yarbrough W. Clinical evaluation of a new molecular method for detection of micrometastases in head and neck squamous cell carcinoma. Arch Otolaryngol Head Neck Surg. 2004;130:937-42.

134. Cochran AJ, Ohsie SJ, Binder SW. Pathobiology of the sentinel node. Curr Opin Oncol. 2008;20:190-5.
135. Thomsen JB, Christensen RK, Sorensen JA, Krogdahl A. Sentinel lymph nodes in cancer of the oral cavity: is central stepsectioning enough? J Oral Pathol Med. 2007;36:425-9.

136. Woolgar JA. Micrometastasis in oral/oropharyngeal squamous cell carcinoma: Incidence, histopathological features and clinical implications. Br J Oral Maxillofac Surg. 1999;37:181-6.

137. von Buchwald C, Bilde A, Shoaib T, Ross G. Sentinel node biopsy: the technique and the feasibility in head and neck cancer. ORL J Otorhinolaryngol Relat Spec. 2002;64:268-74.

138. Rutgers EJ. Sentinel node biopsy: interpretation and management of patients with immunohistochemistry-positive sentinel nodes and those with micrometastases. J Clin Oncol. 2008;26:698-702.

139. Woolgar JA, Beirne JC, Vaughan ED, Lewis-Jones HG, Scott J, Brown JS. Correlation of histopathologic findings with clinical and radiologic assessments of cervical lymph-node metastases in oral cancer. Int J Oral Maxillofac Surg. 1995;24:30-7. 